Article

\title{
Flood Modeling Using a Synthesis of Multi-Platform LiDAR Data
}

\author{
Ashleigh B. Turner ${ }^{1, *}$, Jeffrey D. Colby ${ }^{2}$, Ryan M. Csontos ${ }^{3}$ and Michael Batten ${ }^{4}$ \\ 1 Tuck Mapping Solutions, Inc., Denver, CO 80134, USA \\ 2 Department of Geography and Planning, Appalachian State University, Boone, NC 28607, USA; \\ E-Mail: colbyj@appstate.edu \\ 3 Newmont Mining Corporation, Denver, CO 80134, USA; E-Mail: ryan.csontos@gmail.com \\ 4 HDR Inc., Raleigh, NC 27612, USA; E-Mail: michael.batten@hdrinc.com \\ * Author to whom correspondence should be addressed; E-Mail: aturner@tuckmapping.com; \\ Tel: +1-901-493-9203.
}

Received: 29 July 2013; in revised form: 11 September 2013 / Accepted: 12 September 2013 / Published: 30 September 2013

\begin{abstract}
This study examined the utility of a high resolution ground-based (mobile and terrestrial) Light Detection and Ranging (LiDAR) dataset (0.2 m point-spacing) supplemented with a coarser resolution airborne LiDAR dataset ( $5 \mathrm{~m}$ point-spacing) for use in a flood inundation analysis. The techniques for combining multi-platform LiDAR data into a composite dataset in the form of a triangulated irregular network (TIN) are described, and quantitative comparisons were made to a TIN generated solely from the airborne LiDAR dataset. For example, a maximum land surface elevation difference of $1.677 \mathrm{~m}$ and a mean difference of $0.178 \mathrm{~m}$ were calculated between the datasets based on sample points. Utilizing the composite and airborne LiDAR-derived TINs, a flood inundation comparison was completed using a one-dimensional steady flow hydraulic modeling analysis. Quantitative comparisons of the water surface profiles and depth grids indicated an underestimation of flooding extent, volume, and maximum flood height using the airborne LiDAR data alone. A 35\% increase in maximum flood height was observed using the composite LiDAR dataset. In addition, the extents of the water surface profiles generated from the two datasets were found to be statistically significantly different. The urban and mountainous characteristics of the study area as well as the density (file size) of the high resolution ground based LiDAR data presented both opportunities and challenges for flood modeling analyses.
\end{abstract}


Keywords: LiDAR; airborne; mobile; terrestrial; flood inundation analysis; urban; mountains; HEC-RAS; ArcGIS

\section{Introduction}

Humans have traditionally developed settlements in floodplains and continue to do so, making flood events one of the most consistent and recurring natural disasters experienced by human populations [1-3]. The management of flood risk and the reduction of potential damages in the United States (U.S.) have been addressed by the Federal Emergency Management Agency (FEMA) through mapping flood hazard areas and the generation of Digital Flood Insurance Rate Maps (DFIRMS). The European Commission adopted the European Union (EU) Flood Directive in 2007 [4]. The Directive requires member states to assess the risk of flooding, to map potential flood extent, and to coordinate efforts to reduce flood risk [4]. The National Research Council (NRC) in the U.S. concluded that topographic data is the most important factor in determining the accuracy of flood maps for inland areas [2]. The primacy of topographic data in flood modeling is supported by additional scientific research $[5,6]$. Traditionally, land surface elevation data has been collected using time-consuming ground surveying techniques consisting of total stations, differential GPS units, field tapes, theodolite, micro profilers, national survey maps, and stereoscopic analysis of aerial imagery [7-9]. The elevation surfaces interpolated from the data collected using these methods can produce uncertainty in elevation values up to ten times greater than the acceptable limit set by FEMA for floodplain mapping [2]. Recently, a rapid increase in the adoption of airborne light detection and ranging (LiDAR) data for flood inundation studies has occurred due to the efficient collection of accurate elevation data for features within the landscape.

Although the use of topographic data acquired from airborne LiDAR sensors has provided modelers with a more accurate dataset, challenges still exist when modeling complex urban environments. Urban flood modeling entails resolving surface water movement around buildings and representation of fine scale topographic and blockage effects [10]. Irregular and discontinuous patterns of floodplain depths are caused by the blocking effect of buildings [11]. Heterogeneities within the land surface such as road cambers, pavement curbs, and minute undulations in the topography play a substantial role in diverting overland flow and floodwaters and the lack of accurate representation of these features can drastically alter flood water flow paths [12-14]. High-resolution data is necessary to represent finer scale features in an urban landscape and to investigate how these features affect flood propagation. Elevation data acquired by ground-based mobile and terrestrial LiDAR systems have proven advantageous for representing the landscape at a finer resolution, and for improving the vertical accuracy of topographic feature representation as compared to the elevation data acquired by airborne systems [15-17].

LiDAR is an active remote sensing system which operates by emitting laser pulses of light at high frequencies towards the Earth's surface as a photodiode measures the time it takes for the pulse to return from the surface to the sensor $[7,8]$. The distance to an object is then calculated by multiplying the speed of light by the time elapsed between when the laser pulse is emitted and received and dividing the product by two [18]. Global positioning systems (GPS) and inertial measuring units (IMU) are linked to 
most LiDAR systems to determine location and account for trajectory variability that occurs during the collection process. The popularity of using LiDAR systems has increased due to their rapid data collection capability, high degree of automation, high point density, high level of accuracy, and cost efficiency. These characteristics led the NRC to recommend the creation of a nation-wide elevation dataset based upon LiDAR data in order to enhance floodplain mapping accuracy $[19,20]$.

Flood inundation studies are based on mapping and defining an area covered by water during a flood event. This is typically done by comparing digital water surface elevations with the digital terrain model (DTM) of the bare-earth elevation and indicating where the water surface elevation is above the land surface [21]. Successful floodplain models using airborne LiDAR data have been reported in rural areas where gradual changes in the topography are prevalent (e.g., [22-26]). Alternatively, the use of airborne LiDAR elevation data in an urban environment has been shown to be insufficient with respect to the accurate representation of the finer scale topographic features (e.g., [13,14,27-29]). A limited amount of research has been related to flooding in mountainous areas and the work that has been conducted has utilized airborne LiDAR data (e.g., [30,31]). Even fewer research efforts have been undertaken in urban locations within mountainous sub-basins (e.g., [12]).

Elevation data from mobile and terrestrial LiDAR systems (MLS and TLS, respectively) have been utilized to compensate for inadequate representation of ground surfaces by airborne LiDAR systems (ALS). Fewtrell et al. [14] conducted one of the first flood inundation analyses based on sub-meter resolution elevation data acquired using a mobile LiDAR system in an urban environment and described the utility of such a high resolution dataset. They concluded that gaps found in their dataset were due to the limited field-of-view of their vehicle-based LiDAR system which produced a variety of undesirable artifacts within the floodwater depth grids (i.e., ponding near the data voids). In the current study to compensate for potential data gaps a triangulated irregular network (TIN) based on a composite of airborne, mobile, and terrestrial LiDAR data was generated. Utilizing the airborne data on the periphery of the study area minimized artifacts, such as artificial ponding, and allowed the voids present in the combined mobile and terrestrial (or ground-based) dataset to be filled using an overlapping airborne dataset. In addition, the ground-based bare-earth dataset was used to replace locations within the bare-earth airborne dataset that had become obsolete due to recent construction and restoration projects. While combinations of multi-platform datasets have been attempted in the past (e.g., [9,32-34]), these studies only combined two different platform datasets, typically merging ALS and TLS, or MLS and TLS [35]. To the author's knowledge, the research presented in this paper is unique in that a combination of data from three LiDAR platforms (i.e., airborne, mobile, and terrestrial) was created, therefore capitalizing on the complementary technologies and reducing the data collection weaknesses inherent in each individual system.

The methodology for combining multi-platform LiDAR datasets into a single TIN for flood modeling in an urban environment was explored in this research. The accuracy of the elevation values in this composite dataset was quantitatively compared to a TIN created solely from elevation data acquired from an airborne LiDAR survey. The composite and airborne TINs were then used to generate independent flood modeling results and compared using a one-dimensional (1D) steady flow analysis implemented in the hydraulic model HEC-RAS (US Army Corp of Engineers; Davis, CA, USA). The generation of geospatial geometric data for flood modeling and the representation of flooding extent and depth were undertaken using the geographic information system (GIS) ArcGIS 
(Environmental Systems Research Institute; Redlands, CA, USA), and the ArcGIS hydraulic model extension HEC-GeoRAS (US Army Corp of Engineers; Davis, CA, USA).

To ensure an accurate representation of the study area, surveying of manmade features that intersected the study stream reach was accomplished through the measurement of structures within the all-return mobile and terrestrial LiDAR point clouds. Bridge and culvert information is essential in creating accurate high resolution flood models as they can control variability in velocity, stage height, and flood extents [36,37]; minimizing or estimating their parameters reduces the accuracy of the flood model results. Given the accuracy of the point cloud data, the resultant structural measurements can be considered as accurate as field-grade survey information [38], although a structure accuracy assessment was not completed for this study.

From 1983 to 2003, the state of North Carolina ranked ninth in terms of the highest total flood damages and twelfth in terms of the highest damages per capita in the United States [39,40]. In the Blue Ridge Mountain Province of the Southern Appalachian Mountains in North Carolina, locally intense, short duration precipitation events coupled with the built environment have produced numerous flash floods substantiating the need to better understand local flooding. Appalachian State University in Boone, North Carolina, USA is located in this province and Boone Creek, part of the Upper South Fork of the New River (USFNR) watershed, runs directly through campus. In November 2011, Boone Creek experienced a large amount of precipitation within a few hours causing a flow event that exceeded the bank-full capacity of the channel and consequently flooded several buildings on campus. Due to this and similar preceding events, this reach of Boone Creek was selected as the study area for this research.

In this research, the utility of a high resolution ground-based LiDAR dataset supplemented with an airborne LiDAR dataset for a flood inundation study in a hydraulic modeling and GIS environment was evaluated. The techniques for combining multi-platform LiDAR datasets were described and illustrated. The final composite dataset in the form of a TIN was quantitatively compared to a TIN generated solely from the airborne dataset. The all-return mobile and terrestrial LiDAR point clouds were used to extract structural information from features intersecting the study stream reach. Utilizing both the airborne and composite datasets, flood inundation analyses were completed and the resultant water surface profiles and depth grids were quantitatively compared. Challenges presented in this research included the complexity of attempting to accurately model an urban stream located in a mountainous headwater sub-basin.

\section{Data and Methods}

\subsection{Study Area}

The Boone Creek sub-basin located in the USFNR watershed drains approximately $5.3 \mathrm{~km}^{2}$ (530 hectares) and is characterized by its high-gradient and rugged topography [41]. This study focused on a $1300 \mathrm{~m}$ reach of Boone Creek that flows through the campus of Appalachian State University in Boone, North Carolina, USA (Figure 1). A river can be defined as a mountain river if the gradient of the majority of its channel length is greater than or equal to $0.002 \mathrm{~m} / \mathrm{m}$ [42]. However, portions of its channel may also flow through broad lower gradient valleys. Overall, the steep channel is considered a 
mountain river [42]. The gradient of the reach modeled in the current study was $0.018 \mathrm{~m} / \mathrm{m}$. The hydrology of mountain environments is dynamic in terms of its spatial and temporal complexity [30]. Precipitation can move rapidly into stream channels due to high topographic relief, intense seasonal precipitation, thin soils, sparse vegetation, and the close coupling of stream channels and hillslopes [31].

Extensive development along the banks of Boone Creek has modified natural conditions leading to reduced riparian vegetation, channelization, incised streambeds and banks, and added extensive impervious surfaces surrounding the stream [43]. The primary land cover type of the Boone Creek sub-basin is $60 \%$ non-differentiated forests, with $24 \%$ impervious surfaces, and $16 \%$ is a mixture of grass, barren land, and agriculture [41]. The riparian area bounding Boone Creek (within $50 \mathrm{~m}$ ) is dominated by impervious surfaces (54\%), grasslands (35\%), and non-differentiated forests (10\%). These values were determined by calculating the area of each land use type generated through heads-up digitizing of 2010 6-inch aerial photography and dividing the total area for each land use classification by the total sub-basin or riparian area, respectively.

Figure 1. Study area: (a) Location of the Upper South Fork of the New River (USFNR) watershed in North Carolina. Source: [44]; (b) Hillshade-relief image of the Boone Creek sub-basin located in the USFNR watershed derived from bare-earth airborne LiDAR data. The major streams are indicated in blue while the location of the study stream reach is highlighted in red; (c) Photograph looking upstream on Boone Creek at the open channel and the end of the culvert through which part of the study stream reach flows.

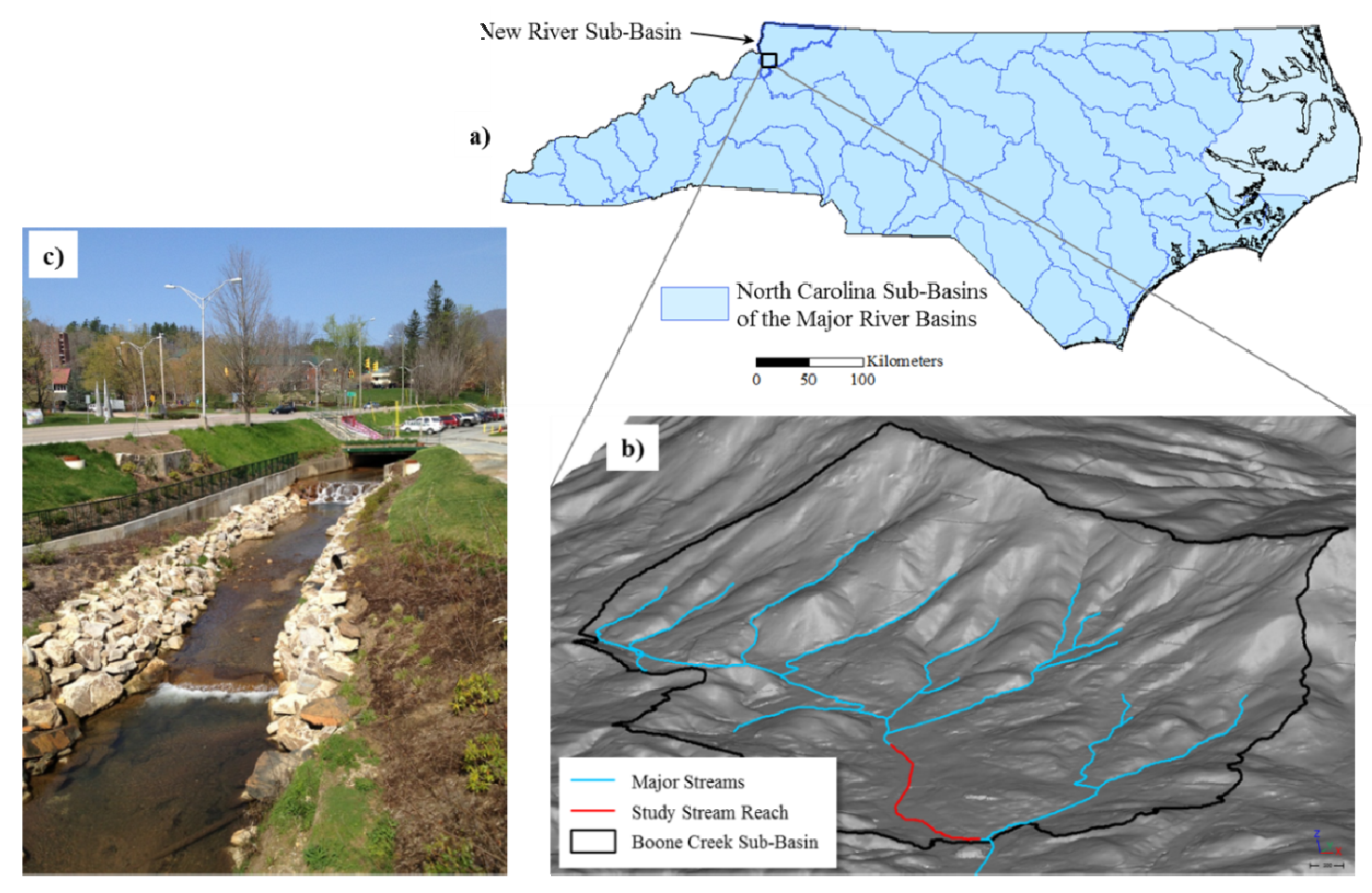

The regional climate is classified as a humid, temperate zone with high levels of precipitation in the spring and summer months, and flood events primarily occurring in late summer and early fall $[41,45]$. Flooding events in the sub-basin are characterized by their high intensity, short duration, and high variability. The predominance of impervious surfaces surrounding Boone Creek and the Hortonian flow associated with this land cover type has led to substantial flood events. 


\subsection{Airborne LiDAR Data Acquisition and Processing}

LiDAR data used in flood modeling applications is typically acquired from airborne platforms and used for the creation of bare-earth DTMs and the estimation of land surface roughness characteristics. Statewide airborne LiDAR data was collected by the North Carolina Floodplain Mapping Program (NCFMP) in an effort to modernize FEMA's Flood Insurance Rate Maps (FIRM) [46]. Airborne LiDAR data for the study region was collected in March 2003 using a Leica Geosystems Aeroscan system. The instrument was flown at an altitude of $3050 \mathrm{~m}$ above ground level producing an all-return point spacing of approximately $5 \mathrm{~m}$ (Table 1). The maximum scan angle was set to 27.5 degrees from nadir with up to five returns per pulse, netting a vertical root mean squared error (RMSE) for this dataset of $25 \mathrm{~cm}$ [46]. Point cloud processing was performed by the NCFMP using automated processes to extract bare-earth points, followed by manual editing to remove any falsely identified points within the bare-earth dataset [46]. The data was organized into $3048 \mathrm{~m}(10,000 \mathrm{ft}$.) by $3048 \mathrm{~m}(10,000 \mathrm{ft}$.) tiles in an ASCII format and have been made available to the public on the NCFMP website [47]. The bare-earth LiDAR tiles covering the selected study stream reach were downloaded from the NCFMP website, converted from the ASCII format to an LAS format to a multi-point shapefile in ArcGIS, and clipped to the study region.

Table 1. Comparative table of the applied LiDAR sensors and data attributes.

\begin{tabular}{llll}
\hline \multicolumn{1}{c}{ Descriptions } & \multicolumn{1}{c}{ Airborne } & \multicolumn{1}{c}{ Mobile } & \multicolumn{1}{c}{ Terrestrial } \\
\hline Scanner system & Leica Geosystems Aeroscan & Trimble MX8 Pod & Leica ScanStation C10 \\
Range & Flown 3050 m AGL & $200 \mathrm{~m}$ & $300 \mathrm{~m}$ \\
Vertical RMSE & $25 \mathrm{~cm}$ & $6 \mathrm{~cm}$ & $3 \mathrm{~cm}$ \\
Measurement rate & $150 \mathrm{kHz}$ & $300 \mathrm{kHz}$ & $50 \mathrm{kHz}$ \\
Field-of-view & $55^{\circ}$ & $360^{\circ}$ & $360^{\circ}$ (horizontal); \\
Nominal all-return point-spacing & $5 \mathrm{~m}$ & $0.05 \mathrm{~m}$ & $270^{\circ}$ (vertical) \\
Acquisition date & March 2003 & July 2011 & $0.005 \mathrm{~m}$ \\
\hline
\end{tabular}

\subsection{Ground-Based LiDAR Data Acquisition and Processing}

Ground-based LiDAR data was collected by ESP Associates, P.A. in July 2011 and donated to Appalachian State University. Vehicle-based mobile LiDAR data was collected for the $1300 \mathrm{~m}$ reach of Boone Creek. Voids within the dataset were observed during post-processing, especially in areas adjacent to the stream due to heavy riparian vegetation blocking the laser scanner's line-of-sight. Static terrestrial LiDAR scans were taken in areas that would fill the data gaps in order to create a complete 3-D dataset.

\subsubsection{Mobile LiDAR}

The mobile LiDAR data were acquired in ten discrete runs using a Trimble MX8 mobile mapping system equipped with two VQ 250 Riegl lasers, six 5-megapixel cameras, one Applanix POS LV 420 IMU, two Trimble Global Navigation Satellite System (GNSS) GPS receivers, and one Distance Measuring Instrument (DMI). The DMI is a wheel-mounted rotary shaft encoder that confines drift 
errors during a loss of GPS signal by measuring the linear distance travelled [48]. Each laser collected 300,000 points per second over a five-kilometer stretch of campus. Photographs were taken every three meters using four separate cameras. The all-return point spacing for the dataset ranged from $0.9 \mathrm{~cm}$ (directly adjacent to the vehicle) to $30 \mathrm{~cm}$ (approximately $200 \mathrm{~m}$ away from the vehicle). The entire dataset was comprised of approximately 425 million points; a list of the mobile sensors attributes and a description of the dataset are listed in Table 1.

\subsubsection{Terrestrial LiDAR}

Eight terrestrial LiDAR scans were acquired to fill the data gaps within the coverage of the mobile LiDAR dataset. A portable Leica ScanStation C10 equipped with a dual-axis level compensator, laser plummet and tribrach mount, and an integrated data storage system was utilized to acquire the terrestrial data. This device collected 50,000 points per second with a range of approximately $300 \mathrm{~m}$. The all-return point spacing ranged from $0.3 \mathrm{~cm}$ (directly adjacent to the scanner) to $15 \mathrm{~cm}$ (approximately $300 \mathrm{~m}$ away from the scanner). The entire dataset was comprised of approximately 89 million points; a list of the terrestrial sensors attributes and a description of the dataset are listed in Table 1.

\subsubsection{Ground Control Points and the Continuously Operating Reference Station}

Survey grade accuracy of the final mobile and terrestrial point clouds were verified via thirty-two ground control points (GCPs) acquired using a Trimble R8 Model 3 GNSS receiver. Control points were placed on recognizable features in the landscape which could later be identified within the point cloud during the registration process. Photographs were taken at each control location in the event the sites were difficult to locate within the point cloud.

A Continuously Operating Reference Station (CORS) was used to enhance the post-processing coordinates to within centimeters relative to the National Spatial Reference System, both vertically and horizontally [48]. A CORS was located on the Rankin Science West Building situated near the center of Appalachian State University campus. The mean distance of the GCPs from the CORS was approximately $0.5 \mathrm{~km}$.

\subsubsection{Mobile and Terrestrial LiDAR Post-Processing}

LiDAR surveys contain points representing bare-earth and non-bare-earth features such as buildings, powerlines, and vegetation, while the manual ground survey methods described earlier typically ignore these features. Therefore, the integrity of a LiDAR-based bare-earth dataset depends on the quality of the bare-earth points extracted from the all-return point cloud and the removal of additional features within the dataset. Post-processing of the mobile and terrestrial LiDAR datasets was required to ensure the point clouds could be seamlessly merged into one ground-based LiDAR dataset and that the ground-based point cloud could be tied to real world coordinates then merged and compared to the existing bare-earth airborne dataset.

Post-processing of the GPS files from the Trimble MX8 Mobile Scan Pod to the local CORS was completed using POSPac Mobile Mapping Suite Version 5.1 (Applanix; Ontario, Canada). This process uses the concept of a "Virtual Reference Station" (VRS) where "observables from a dedicated 
network of GNSS reference stations are processed to compute the atmospheric and other errors within the network" [49]. The output information from the DMI and IMU was integrated and post-processed in forward and reverse directions which refined the data and produced the best possible results [49]. This information was used to "normalize" the mobile LiDAR data fitting the point cloud with the proper trajectory (i.e., path of the sensor during the collection process).

The mobile and terrestrial LiDAR point clouds were then registered to real world coordinates via the GCPs using the Match Point process in Trident-3D Analyst Version 4.5 (Trimble; Sunnyvale, CA, USA). For this registration, the GCPs were manually "matched" to their corresponding locations within the point cloud and a "best fit analysis" was used to rectify the point cloud to the GCPs, ensuring survey-grade accuracy. Prior to the GCP registration, the mobile data points were approximately $6 \mathrm{~cm}$ lower than the GCPs, while the terrestrial data points were approximately $3 \mathrm{~cm}$ lower than the GCPs. The registered mobile dataset was approximately $2 \mathrm{~cm}$ lower than the GCPs while the registered terrestrial dataset was approximately $1 \mathrm{~cm}$ lower. The error present following the correction is due to the inherent trajectory drift of the mobile LiDAR platform, the irregularities of the terrain, and the methods used in the Trident-3D Analyst Match Point process. Additionally, this process was used to merge the mobile and terrestrial LiDAR datasets by using a tie-point-based co-registration process. This combination yielded a $3 \mathrm{~cm}$ vertical RMSE between the two datasets.

The co-registered ground-based all-return point clouds were then divided into 14 discrete blocks using the Place Fence tool in MicroStation V8 (Bentley Systems; Dublin, Ireland) to create manageable sub-datasets and reduce processing time (Figure 2). Point cloud classification consisting of identifying and classifying noise as well as extracting bare-earth points was completed using TerraScan software (Terrasolid; Helsinki, Finland). Initially, the Low Points and Isolated Points routines were used to reduce the amount of erroneous or 'noisy' points within the dataset.

Figure 2. The study area segmented into 14 discrete blocks for the creation of manageable datasets. Blocks were generated using the Place Fence tool in MicroStationV8.

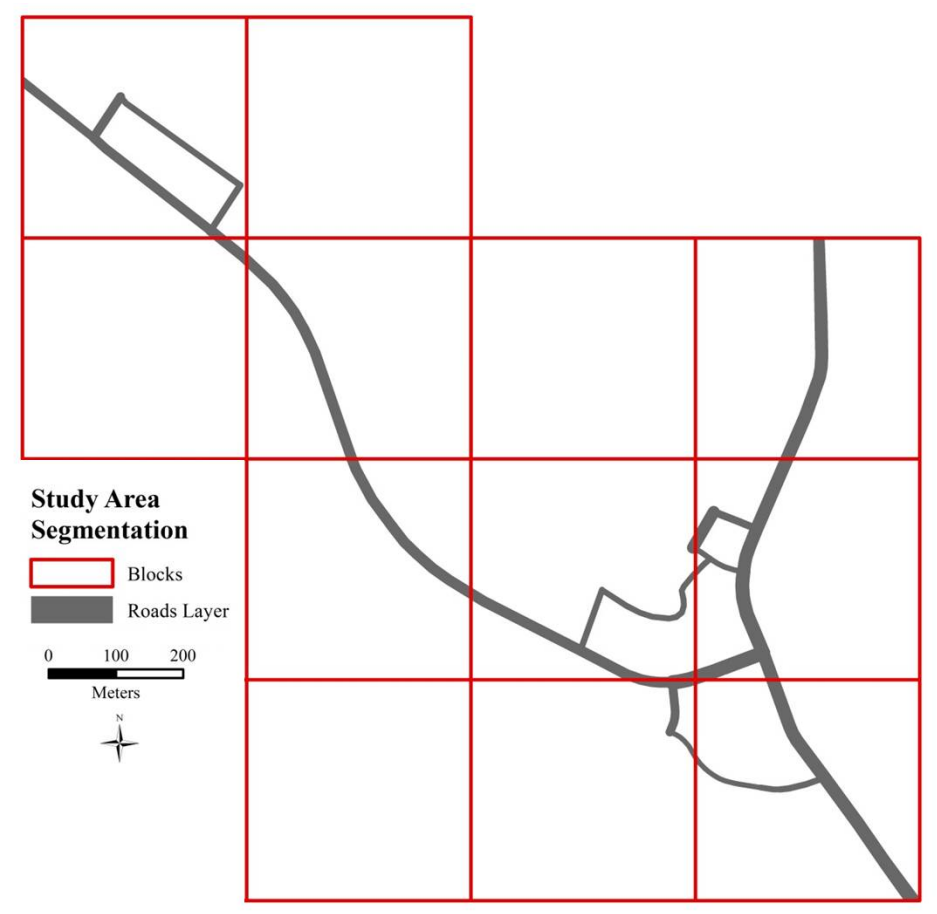


The Ground routine provided by TerraScan was used to extract bare-earth points using an algorithm based on the adaptive TIN model created by Axelsson [50]. The algorithm develops a TIN network from neighboring low points as a first iteration of the bare-earth extraction. Then, based on the user-defined input values, the TIN was modified by adding additional points that met the user-defined criteria in relation to the existing TIN. The user-defined values utilized by the Ground routine consist of the maximum building size in the area, the maximum terrain angle in the study area (i.e., the steepest slope), the iteration angle (i.e., the angle of the triangles within the adaptive TIN model being generated), and the iteration distance (i.e., the length of the triangle within the adaptive TIN model being generated). Superior results were obtained during point cloud classification by further segmenting the blocks into areas of homogeneous land cover and topography and utilizing different iteration angle and iteration distance values. Segmentation of the blocks into homogeneous areas was completed using the Place Fence tool in MicroStation V8.

Points located below the classified bare-earth points were identified using the Below Surface routine from TerraScan. Classification accuracy was completed using visual assessment in TerraScan and LP 360 (QCoherent; Madison, AL, USA) by inspecting random locations within the study area in a profile view. Areas that appeared to have multiple incorrectly classified ground points were reclassified using new iteration angle and iteration distance values. The final classified ground points from each block were merged into one file and consisted of approximately 44 million points. Figure 3 is an example from the datasets displaying the differences between the all-return and bare-earth point clouds.

Figure 3. A visual comparison between (a) the all-return co-registered ground-based point cloud and (b) the co-registered ground-based bare-earth classified point cloud.
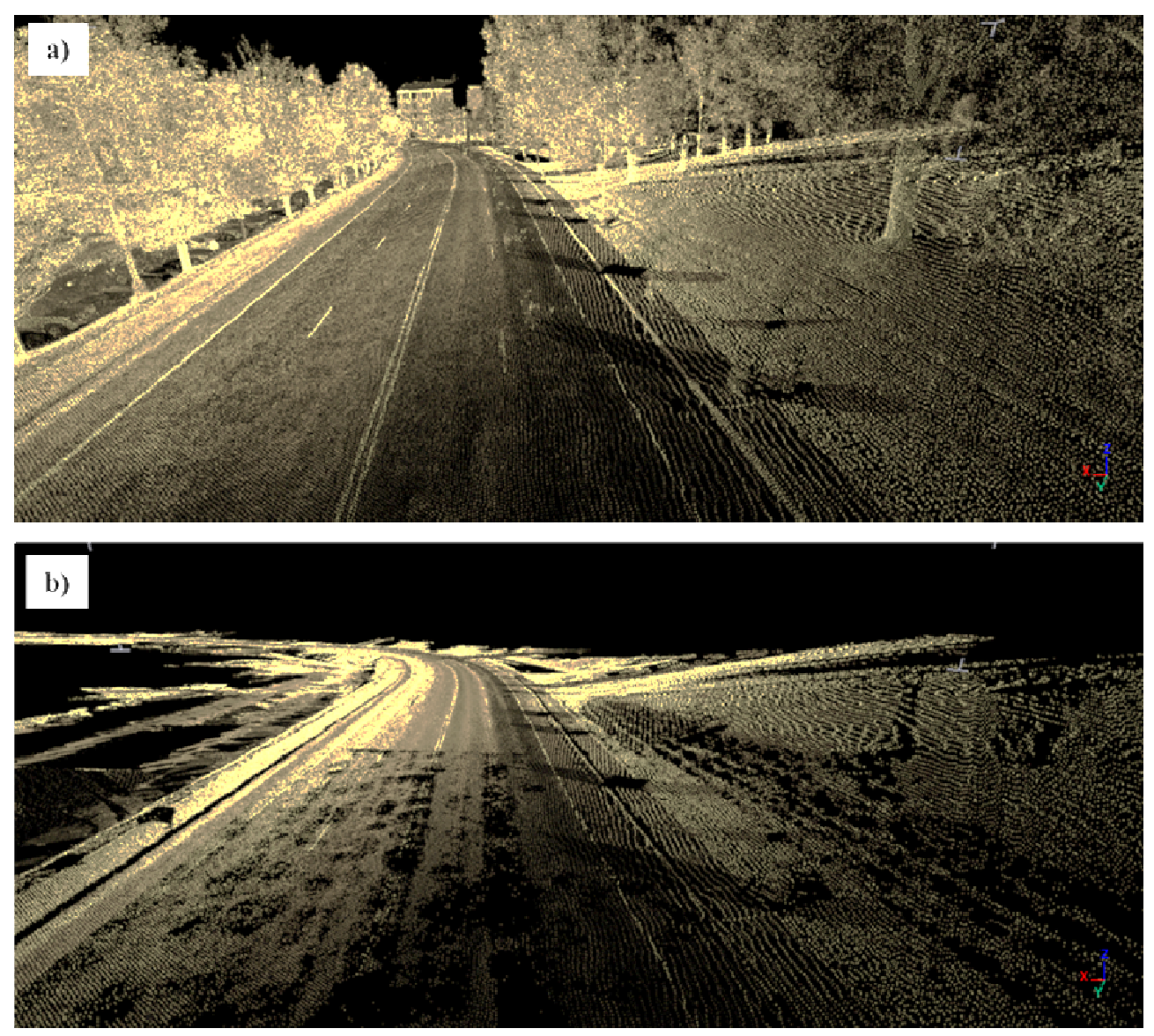


\subsubsection{Synthesis of Airborne and Ground-Based Bare-Earth LiDAR Data and TIN Generation}

The tie-point-based co-registration process used to merge the mobile and terrestrial LiDAR data was utilized because the GCPs within the study area could be identified within each point cloud. Due to the coarser resolution of the airborne LiDAR data, the GCPs could not be identified within the airborne LiDAR point cloud. Therefore, the synthesis of the georeferenced airborne and ground-based LIDAR datasets was completed by displaying the two point clouds in the same reference system. While this method is not as exact as the tie-point-based registration, the identical projection and coordinate system of these two datasets allows for a synthesis which potentially produced vertical differences up to $20 \mathrm{~cm}$ where the two datasets intersect. Seventy-five percent of the composite dataset was comprised of the ground-based LiDAR data representing the areas adjacent to the stream and in the floodplain. The remaining $25 \%$ of the composite dataset consisted of the airborne LiDAR data which was located on the periphery and was used to fill in areas not scanned by the ground-based sensors.

TINs necessary for the flood inundation analysis were generated from the bare-earth LiDAR datasets within ArcGIS. ArcGIS was not capable of processing the entire ground-based bare-earth LiDAR point clouds in a single pass (over 44 million points); therefore, the airborne and composite point clouds were segmented into six sub-areas with overlapping adjacent cross-sections described later in the flood modeling section. To retain the high resolution integrity of the dataset, segmentation into sub-areas was determined to be the most reliable approach. Two TIN datasets for each sub-area were created, one from the bare-earth airborne LiDAR dataset and one from the bare-earth composite dataset consisting of airborne, mobile, and terrestrial LiDAR data. TINs generated from the bare-earth airborne LiDAR data contained an average point spacing of $5 \mathrm{~m}$ and the bare-earth composite TIN yielded a weighted average point spacing of $0.2 \mathrm{~m}$ (Figure 4).

Figure 4. A composite triangulated irregular network (TIN) consisting of the merged bare-earth airborne, mobile, and terrestrial LiDAR data. The location of the ground-based LiDAR data is contained within the red polygon.

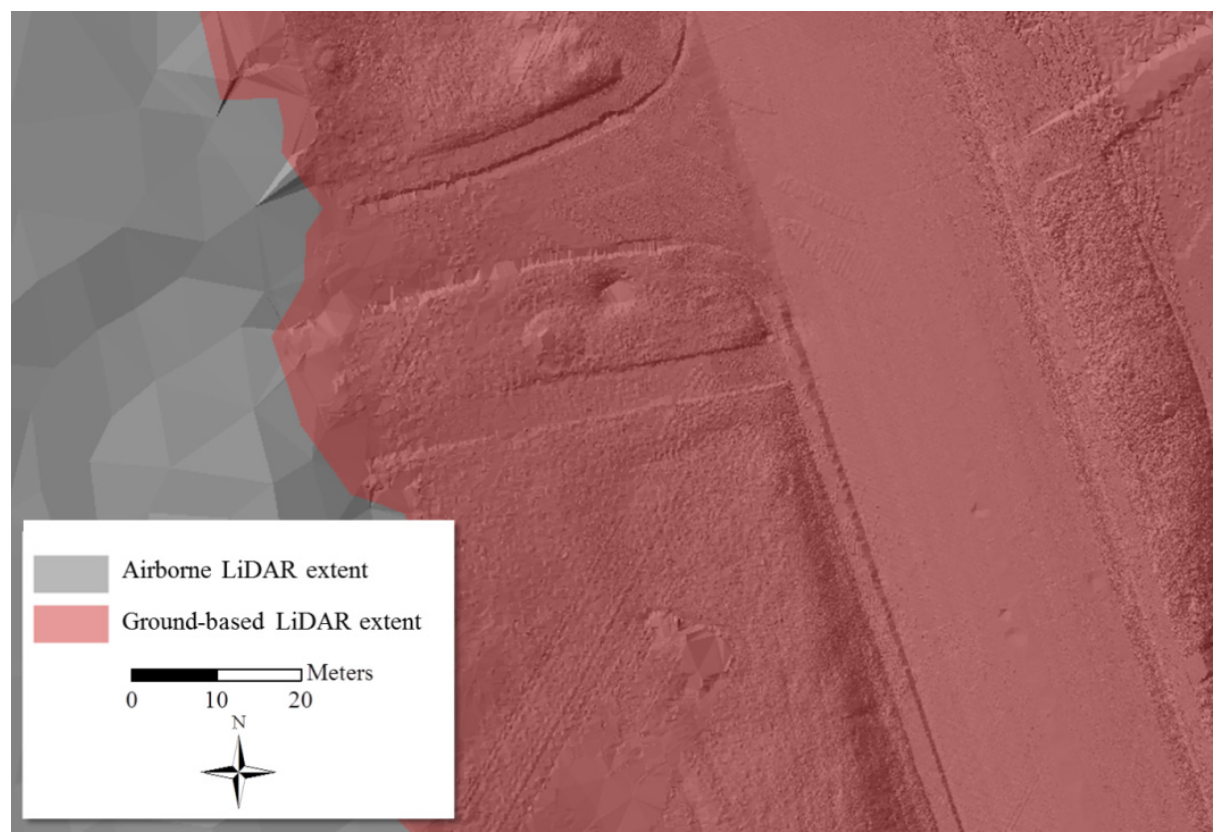




\subsection{LiDAR Data Quality in the U.S.}

According to Mark et al. [5], the use of up to $5 \mathrm{~m}$ horizontal resolution DTMs are recommended for urban flood modeling. A $5 \mathrm{~m}$ resolution DTM can be used for quick assessment of model results, while more detailed analysis should be based on finer resolution DTMs [5]. In the U.S. the National Digital Elevation Program (NDEP) sponsored the National Enhanced Elevation Assessment (NEEA) which was completed in December of 2011 [51]. The results from the NEEA led to the implementation of the 3D Elevation Program (3DEP) developed by the U.S. Geological Survey (USGS). The NEEA identified 5 Quality Levels (QL) for topographic data, and the source of the three highest Quality Levels were LiDAR data [19]. The goal of the 3DEP is to develop Quality Level 2 data (vertical RMSE of $9.25 \mathrm{~cm}$ and nominal point spacing of $0.7 \mathrm{~m}$ ) for the conterminous U.S. Federal organizations such as FEMA would certainly benefit from this enhanced elevation data. Currently, however, only $28.4 \%$ of the lower 49 states have LiDAR data that is available to the public [19]. With a nominal point spacing of $5 \mathrm{~m}$ and a vertical accuracy of $25 \mathrm{~cm}$ the airborne LiDAR data used in this study would be considered medium to low quality (QL3/QL4). Nevertheless, the use of this elevation data has led to risk avoidance and significant cost savings for businesses and residents [19], and is currently the only statewide LiDAR data available in North Carolina. With a nominal point spacing of $0.2 \mathrm{~m}$, and a plus or minus $3 \mathrm{~cm}$ vertical RMSE, the composite LiDAR dataset would be considered better than the QL 1 [19]. It would be informative to compare DTMs and urban flood modeling results generated from these two LiDAR datasets.

\subsection{LiDAR Accuracy Assessments}

Several diagnostic tests were used to evaluate the processed bare-earth datasets. The first diagnostic method evaluated the accuracy of the LiDAR data in relation to the National Spatial Reference System (defined and managed by the National Geodetic Survey) to ensure the LiDAR data met the vertical accuracy and precision of survey-grade data to enable reliable mapping. At the location of the thirty-two GCPs, elevation values were extracted from the bare-earth airborne and composite TIN datasets and quantitatively compared to the elevation values of the GCPs. TINs were used for the comparison due to a lack of point-to-point agreement between the GCPs and the airborne LiDAR dataset.

The second diagnostic method quantitatively evaluated the differences between the airborne LiDAR and composite LiDAR bare-earth datasets on three different land surface features. Grass, pavement, and slopes greater than 15 degrees were selected based on the work of Bremer and Sass [9] and the experience of the authors. For comparison, 18 random points within each land surface type were generated throughout the study region using the Create Random Points tool in ArcGIS. Elevation values were extracted at these random points from the airborne and composite TIN datasets, respectively, and descriptive statistics were calculated.

The third diagnostic method compared the airborne and composite LiDAR datasets using 120 randomly generated points from throughout the entire study region. Random points were generated, irrespective of land surface features, and elevation values were extracted from both TIN datasets and quantitatively compared. The final diagnostic involved the generation of 12 random cross-sections that intersected the study stream reach perpendicularly. Elevation values from both TIN datasets were 
extracted along the cross-sections using the Interpolate Shape tool in ArcGIS and the values were displayed and compared in a line graph format.

\subsection{Flood Modeling}

Flood modeling is the digital reconstruction and prediction of the flooding depth and extent of a particular flooding source for a given stream [2]. This is typically completed by comparing digital water surface elevations to digital representations of the ground elevation and indicating where the water surface elevation is above the land surface. A commonly used floodplain hydraulics model [52] and the primary software utilized by FEMA when generating the Digital Flood Insurance Rate Maps (DFIRMs) is the Hydrologic Engineering Center's River Analysis System (HEC-RAS). This model is used for determining remedial and preventative measures for reducing flood damages to a community through the creation of hydraulic studies and flood maps. These maps are used to determine flood insurance rates for property owners that purchase flood insurance through the National Flood Insurance Program (NFIP) and are also used as the basis for regulations for determining building codes and where and what types of structures are allowed in floodplains.

One-dimensional hydrodynamic flood models are an industry standard [12]. HEC-RAS, which was used in this study and is available in the public domain, provides "one-dimensional steady flow, unsteady flow, sediment transport/mobile bed computations, and water temperature modeling" [53]. One-dimensional hydrodynamic modeling provides rapid, simple, but representative calculations for a network of natural and artificial streams, including the representation of manmade objects such as bridges, culverts, and weirs [40,54]. Due to a portion of the study stream reach being contained within a culvert, HEC-RAS provided the necessary methodologies to include this structure within the flood model. Additional information such as bridge and culvert dimensions and material type or blocked obstructions (i.e., buildings) were added to improve the model and resultant water surface profiles and depth grids.

Combining 1D modeling and GIS can provide a cost efficient system for management and planning for urban flooding [5]. The tradeoffs in using a 1D, two-dimensional (2D), or combined 1D/2D hydraulic model for urban flood modeling have been reported in the literature [5,12]. The flashy character of the Boone Creek sub-basin encouraged a 1D hydraulic modeling approach, as one-dimensional hydraulic models are useful for modeling urban flooding during heavy rainfall events [5,12]. For an initial comparison of flood modeling efforts which included a coarser resolution dataset $(5 \mathrm{~m})$ with a lack of fine scale feature representation the use of a $2 \mathrm{D}$ or $1 \mathrm{D} / 2 \mathrm{D}$ model may not be necessary. Further research using $2 \mathrm{D}$ or combined $1 \mathrm{D} / 2 \mathrm{D}$ models focusing on the use of finer resolution LiDAR data in steep mountainous environments would be useful.

\subsubsection{Input Data}

Discharge rates and water surface elevations for a 100-year flood event were obtained from the 2009 Flood Insurance Study (FIS) produced by FEMA in the State of North Carolina [55]. Real-time floodwater measurements, i.e., stream gages, were not available for an event of this magnitude. Proxies such as eyewitness testimonies on the location of high water marks were used to estimate flood water extents, as have been used in similar studies [12]. Discharge rates were utilized in the model at every 
cross-section cut line location. Water surface elevation values were utilized at the upstream and downstream cross-section cut lines of the study stream, as well as locations where culverts or bridges intersected the stream.

\subsubsection{Flood Modeling Using HEC-RAS and ArcGIS}

Geometric input data for HEC-RAS, consisting of stream centerlines, banks, flow-paths, cross-section cut lines, land use polygons, and blocked obstructions were digitized from 2010 6-inch orthoimagery (Figure 5) within ArcGIS using HEC-GeoRAS. HEC-GeoRAS is a "set of procedures, tools, and utilities for processing geospatial information data in ArcGIS using a graphical user interface (GUI)" [56]. HEC-GeoRAS tools were used to extract and prepare geometric data for HEC-RAS and post-processing of the results from the flood analysis generated by HEC-RAS. For example, using HEC-GeoRAS, land use polygons were attributed with the appropriate Manning's n (roughness coefficient) values determined by Chow [57], based on surface roughness, vegetation, surface irregularities, and obstructions.

Cross-section cut lines were digitized from the orthoimagery and drawn perpendicular to the stream, stream banks, flow-paths, and contours. Cross-sections were placed at "intervals along [the] stream to characterize the flow carrying capacity of the stream and its adjacent floodplain" [58]. Cross-sections are necessary at representative locations along the stream reach where changes in discharge rates, streambed slope, shape, and surface friction or roughness occur, or at structures such as bridges and culverts. Cross-section placement is critical in that they contain information related to elevation, the intersection of other geometric data (i.e., stream centerlines or flow-paths or blocked obstructions), roughness coefficients, reach lengths (i.e., distance between cross-sections), and discharge values. The amount of cross-sections recommended by HEC-RAS for an area similar to the study stream reach was doubled to better exploit the high resolution LiDAR terrain data.

Figure 5. Geometric data consisting of stream centerline, stream banks, cross-section cut lines, flow-paths, blocked obstructions, and land use polygons were digitized from 2010 6-inch orthoimagery [44] for the flood inundation study.
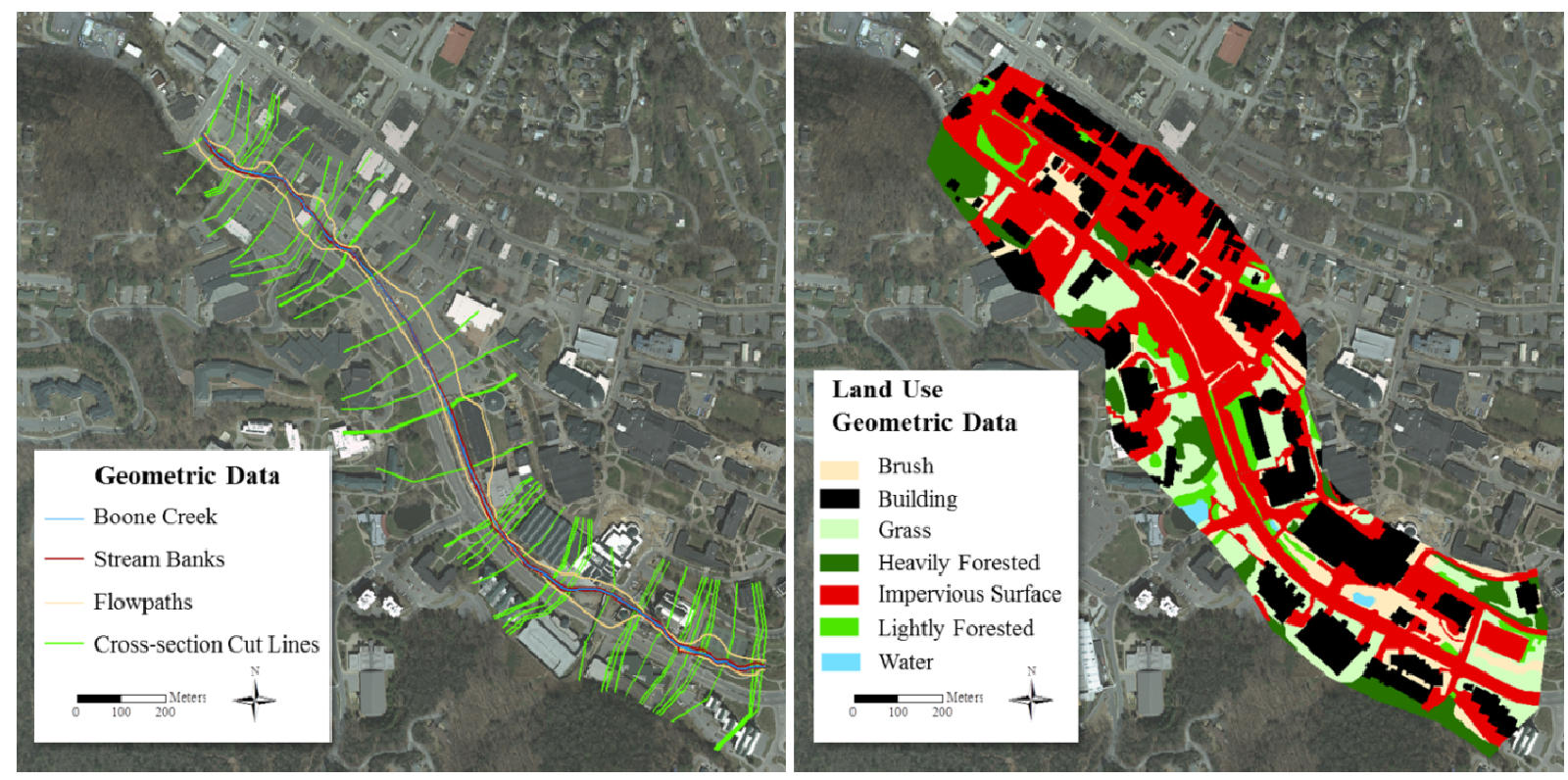
The geometric data and corresponding TIN derived cross-section station-elevation points were exported from ArcGIS using HEC-GeoRAS into HEC-RAS for use in a 1D steady flow analysis. Cross-section elevation points had to be processed using a near and collinear point filter to reduce the point density of the elevation data along the cross-section cut lines, as HEC-RAS is limited to using 500 points per cross-section cut line. Approximately $700 \mathrm{~m}$ of the study stream reach flowed through a culvert increasing the complexity of the model. Bridge and culvert structural information necessary to maintain the accuracy of the flood model were extracted from the all-return mobile and terrestrial LiDAR point clouds. The structural measurements consisted of high and low chord elevations, length and width of the bridge, rise and span of the culvert, and qualitative assessments of the pipe material and shape (Figure 6). All structural information from the point cloud was entered into the Deck/Roadway and Culvert Data Editor in HEC-RAS to generate bridges and culverts in the model that intersected the study stream reach.

Figure 6. Structure measurements within the all-return mobile and terrestrial LiDAR point clouds of a bridge and culvert in the study area. (a) Photograph of the bridge and culvert being assessed; (b) Measurements of the rise and span of the culvert; (c) Measurements of the bridge length and width; (d) Highest elevation (high chord) measurements taken on the upstream and downstream side of the bridge. The numerical values represent the $\mathrm{X}, \mathrm{Y}$, and $\mathrm{Z}$ of the point being obtained.
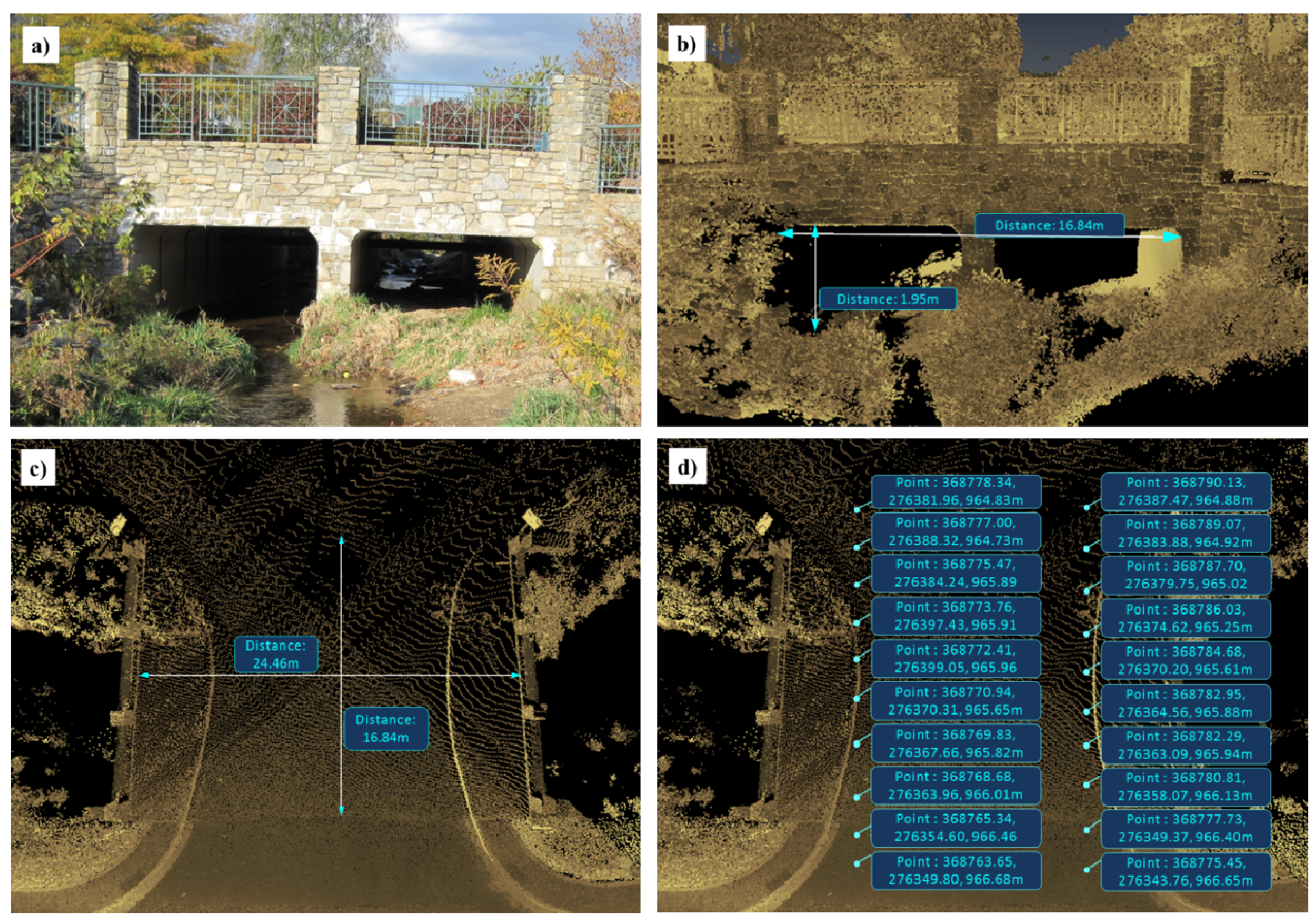

Hydrologic data (discharge rates and water surface elevation) obtained from the FIS produced by FEMA [55] was entered into the Steady Flow Analysis tool in HEC-RAS. Identical planimetric 
geometric data and hydrologic values were used for the HEC-RAS models based on the airborne and composite LiDAR terrain datasets. A Steady Flow Analysis was run using HEC-RAS to generate flood extents in the form of water surface profiles for each terrain dataset. The cross-section station-elevation data of the water surface profiles were exported from HEC-RAS into ArcGIS. Using HEC-GeoRAS, the water surface data in conjunction with the terrain elevation data was used for floodplain delineation and the generation of depth grids. The first step was to create a water surface TIN from the water surface elevation values attached to the cross-sections exported from HEC-RAS. The water surface TIN was created apart from the terrain TIN and clipped to the bounding polygon (exported from HEC-RAS) which limits the water surface to areas modeled using HEC-RAS. The water surface TIN and terrain TIN were then rasterized with a resolution based on the point-spacing of the respective terrain dataset and the floodplain was delineated where the water surface elevations were higher than the terrain elevations. The rasterized terrain elevation values were subtracted from the rasterized water surface elevation values to create the depth grids. The sub-area flood modeling results were merged into seamless water surface profiles and depth grids representing the airborne and composite LiDAR datasets, respectively.

\subsubsection{Flood Modeling Diagnostics}

Several diagnostic methods were used to compare the flood modeling results generated using the two different datasets. Following the work of Colby and Dobson [31], a diagnostic method was applied to compare the horizontal extent of the water surface profiles (WSPs) using 60 randomly stratified transect lines drawn perpendicular to the study stream reach (Figure 7). The intersection of the two WSPs and the transect lines was computed and the distance flooded along each transect was calculated for each dataset. The distances flooded were tested for normality and were found to be normally distributed for both datasets. Therefore, a parametric Paired-T test was performed to determine whether statistically significant differences existed between the distances flooded along the transects between datasets. The mean percentage of distances flooded along the transects was also calculated using the formula provided by Colby and Dobson [31]. Additionally, the shape and area of the WSPs were evaluated based on a symmetric difference calculation [31,59] [Equation (1)]:

$$
\text { Error }(\%)=\frac{\text { Area }(\text { Airborne })+\text { Area }(\text { Composite })-2 \cdot \text { Area }(\text { Airborne } \cap \text { Composite })}{\text { Area }(\text { Composite })} \cdot 100
$$

where Area (Airborne) refers to the area of the airborne LiDAR-derived WSP; Area (Composite) refers to the area of the composite LiDAR-derived WSP; and Area (Airborne $\cap$ Composite) refers to the intersection of the airborne and composite WSPs. The resultant value represents the percent error (i.e., symmetric difference) of the airborne LiDAR-derived water surface profile compared to the composite LiDAR-derived water surface profile.

The volumes of the modeled depth grids were calculated using the Surface Volume tool in ArcGIS. For each depth grid cell, the volume was determined by multiplying the area of the cell (length times the width or the resolution squared) by the depth value for that cell then taking the sum of the volumes for all of the cells. This was completed for both the airborne LiDAR and composite LiDAR-derived depth grids and the resultant unit of measure was cubic meters. Maximum flood height was also calculated. The differences between the depth grids were evaluated by subtracting the depth grid 
derived using the composite dataset from the depth grid derived using the airborne dataset. The root mean squared error (RMSE) between the airborne LiDAR and composite LiDAR-derived depth grids was calculated by resampling the airborne depth grid resolution to match the resolution of the composite depth grid to ensure a one-to-one match for each cell volume calculation.

Figure 7. Randomly stratified transect lines drawn perpendicular to the study stream for use in a flood modeling diagnostic. The intersection of the water surface profiles and the transect lines were computed in ArcGIS and the distance flooded along each transect was calculated. (a) Original transect lines; (b) Transects clipped to the intersection of the airborne LiDAR-derived water surface profile; (c) Transects clipped to the intersection of the composite LiDAR-derived water surface profile.

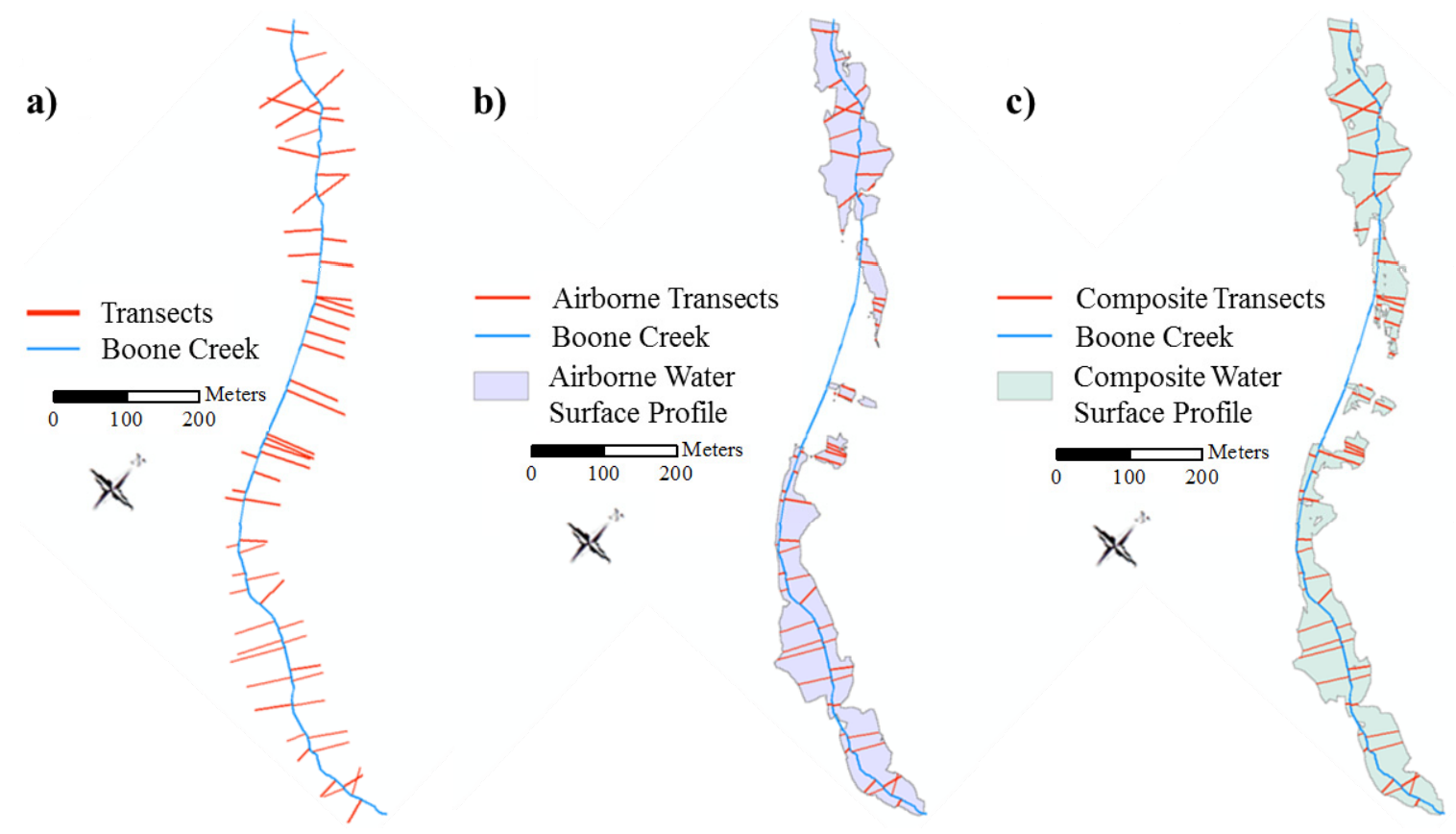

\section{Results and Discussion}

\subsection{Bare-Earth LiDAR Accuracy Assessment and Comparison}

Table 2 indicates the differences in elevation values between the 32 GCPs and the bare-earth airborne and composite LiDAR TIN datasets, respectively. While the ground-based LiDAR dataset was registered to the GCPs, errors associated with LiDAR collection (i.e., line-of-sight, beam divergence, beam grazing, land cover) still affected the accuracy of the data. However, based on the results, the composite dataset was determined to provide a more accurate representation of the land surface. The variation between the two TIN datasets is assumed to be due to the point-spacing (density) of the airborne dataset in addition to the inherent error associated with airborne LiDAR data collection compared to ground-based LiDAR data collection.

The evaluation of the relative measurement inaccuracies between the airborne-LiDAR TIN and the composite-LiDAR TIN were compared for the same vertical position on three land surface features (Table 3). The least amount of difference between the two datasets was found on paved surfaces due to the planar surface characteristics. The greatest differences in elevation values were found on sloped 
surfaces greater than 15 degrees where data density played a key role in defining the subtleties found on irregularly sloping terrain surfaces. Grasslands produced a range of values falling between the paved and sloping surfaces during the comparison due to its irregular yet nearly flat surface. Although the differences were not extensive on paved surfaces, the complexity of the study area was not fully captured by the airborne LiDAR data which could affect the outcome of the final hydraulic modeling results.

Table 2. Differences between the ground control point (GCP) elevation values and elevation values from the bare-earth airborne and composite LiDAR TIN datasets.

\begin{tabular}{lcc}
\hline \multicolumn{1}{c}{ Statistics } & GCP minus Airborne & GCP minus Composite \\
\hline Mean Difference $[\mathrm{abs}]^{*}(\mathrm{~m})$ & 0.133 & 0.081 \\
Maximum Difference $(\mathrm{m})$ & 0.800 & 0.616 \\
Range $(\mathrm{m})$ & 0.962 & 0.619 \\
Standard Deviation & 0.193 & 0.145 \\
\hline
\end{tabular}

Note: $*$ The mean absolute value was used to ensure an underestimation of differences did not occur.

Table 3. Differences between bare-earth airborne and composite LiDAR TIN elevation datasets on various land surface types found by subtracting the composite TIN elevation values from the airborne TIN elevation values.

\begin{tabular}{lccc}
\hline \multicolumn{1}{c}{ Statistics } & Pavement & Grass & Slope \\
\hline Mean Difference $[\mathrm{abs}](\mathrm{m})$ & 0.074 & 0.068 & 0.230 \\
Maximum Difference $(\mathrm{m})$ & 0.215 & 0.228 & 1.416 \\
Range $(\mathrm{m})$ & 0.239 & 0.451 & 2.013 \\
Standard Deviation & 0.071 & 0.099 & 0.412 \\
\hline
\end{tabular}

An additional analysis comparing the elevation values from the respective TIN datasets at 120 random locations within the entire extent of the study region was conducted. The elevation values from the composite LiDAR TIN were subtracted from elevation values from the airborne LiDAR TIN at each location (Table 4). The range between elevation values was calculated to be $2.7 \mathrm{~m}$ with a maximum difference in elevation values of $1.677 \mathrm{~m}$. Again, this variation was likely due to the density of the airborne LiDAR data, differentiation of data acquisition technologies, and the topographic characteristics of the study area.

Table 4. Difference in elevation values between the bare-earth airborne and composite LiDAR TIN datasets at 120 random locations throughout the study region. Values were determined by subtracting the composite elevation values from the airborne elevation values.

\begin{tabular}{lc}
\hline \multicolumn{1}{c}{ Statistics } & Airborne minus Composite Elevation Values \\
\hline Mean Difference $[\mathrm{abs}](\mathrm{m})$ & 0.178 \\
Maximum Difference $(\mathrm{m})$ & 1.677 \\
Range $(\mathrm{m})$ & 2.730 \\
Standard Deviation & 0.335 \\
\hline
\end{tabular}

A comparison of land surface characteristics captured in the respective TIN datasets was conducted through the generation of twelve random cross-sections drawn perpendicular to the study stream reach 
(example in Figure 8). While numerical differences between elevation values within the two datasets was on average $0.178 \mathrm{~m}$, visual comparison of the cross-sections illustrated the inaccurate representation of critical features within the landscape by the airborne LiDAR TIN. For example in Figure 8, the location of the stream centerline in the airborne LiDAR TIN cross-section is approximately $3.17 \mathrm{~m}$ north (horizontally) and approximately $1 \mathrm{~m}$ higher (vertically) than the actual stream centerline as represented in the composite LiDAR TIN dataset. During the ground-based data collection, the stream was less than $0.25 \mathrm{~m}$ deep in several locations. The composite dataset captured undulations in the terrain that are not present in the airborne data. These differences in terrain representation translate into potentially divergent floodwater flow paths and may alter the direction and velocity of flow in urban environments.

Figure 8. An example of one of twelve cross-sections drawn perpendicular to the study stream reach for elevation value extraction. (a) Aerial view of the cross-section location within the study area on 2010 6-inch orthoimagery [44]; (b) Profile view of elevation values extracted along the cross-section from the bare-earth airborne LiDAR TIN dataset and bare-earth composite LiDAR TIN dataset.

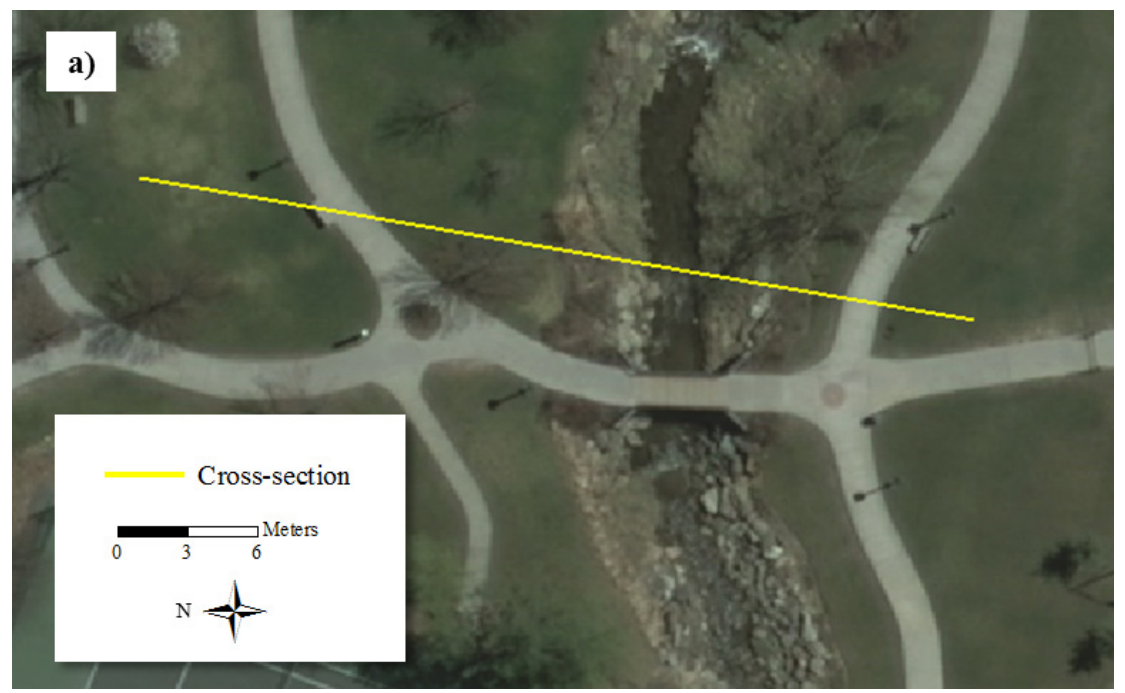

b)

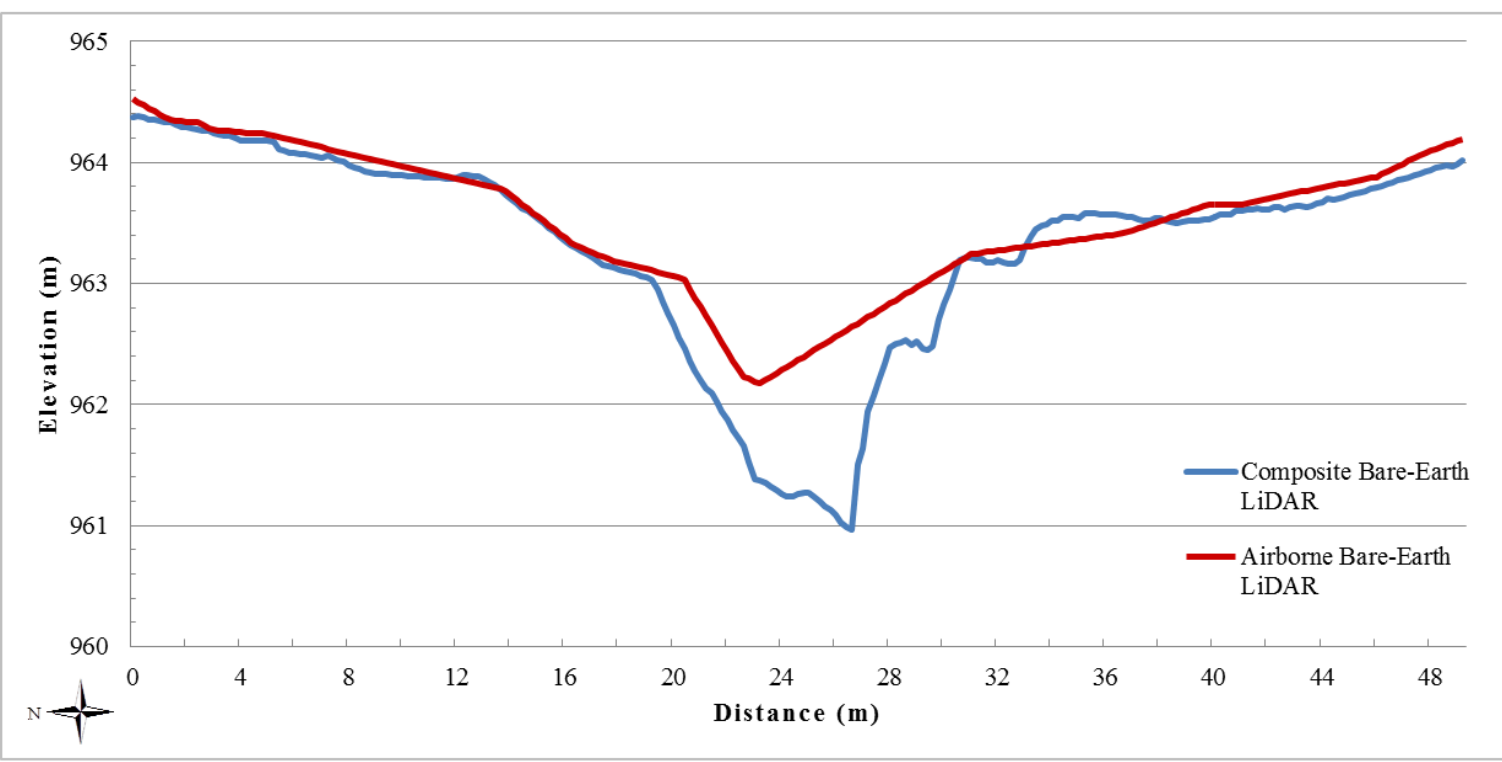




\subsection{Flood Modeling Results}

The flood modeling results generated from the two TIN datasets revealed both similarities and differences between the water surface profiles and depth grids. In the first diagnostic test comparing the elevation values of the two datasets, the composite dataset was found to be more accurate and representative of the actual land surface and theoretically would, therefore, provide a more accurate representation of flooding extent and depth. Discrepancies between the water surface profiles generated from the two datasets are visually evident (Figure 9), and Table 5 provides some quantitative differences. An $8 \%$ increase in water surface area was produced using the composite LiDAR dataset; in addition, using the randomly stratified transect diagnostic method, the average distance flooded and the mean percentage of transects flooded were both greater for the composite LiDAR-derived water surface profile. The results of the Paired-T test, whose null hypothesis was that there was no difference between the sets of distance flooded measurements at a 0.05 significance level, indicated that distances flooded along the transects were statistically significantly different between the airborne and composite LiDAR-derived water surface profiles. This was based on the rejection of the null hypothesis due to the $0.039 p$-value. This difference may be caused by an overestimation of bare-earth elevation values in the airborne LiDAR dataset. Furthermore, representation of complex flow paths within the composite dataset may have also directed the water into lower relief areas not captured in the coarser resolution airborne LiDAR dataset. An example of this can be illustrated by the symmetric difference value that indicates the amount of variation in area and shape between the two water surface profiles (Table 5). The 17.76\% symmetric difference is illustrated in Figure 9 which highlights the location of those differences and how they could affect nearby structures.

Depth grids generated from the two TIN datasets are illustrated in Figure 10. Perhaps the most significant difference between the flood model results was the maximum flood height (Table 6). A 35\% increase in maximum flood height was recorded using the composite LiDAR elevation dataset. While a retention pond had been added to the study area between the time of the airborne and ground-based LiDAR data collection, the differences between the data sets are still representative. It should be stated that the maximum flood height value within the composite LiDAR-derived depth grid did not occur at the retention pond location and was located in a region that had not undergone restoration between the dates of data acquisition. The RMSE between the depth grids was calculated as $1.36 \mathrm{~m}$. These differences also underscore the utility of obtaining and utilizing not only a high resolution dataset but also a current and representative dataset.

Table 5. Quantitative comparison of parameters between the water surface profiles generated using the bare-earth airborne and composite LiDAR datasets.

\begin{tabular}{lccc}
\hline \multicolumn{1}{c}{ Statistics } & Airborne & Composite & Percent Different \\
\hline Area $\left(\mathrm{m}^{2}\right)$ & $55,238.94$ & $59,887.62$ & $8.08 \%$ \\
Average Transect Distance Flooded (m) & 25.59 & 28.44 & $10.55 \%$ \\
Mean Percentage of Transects Flooded & 48.36 & 51.98 & $7.22 \%$ \\
\hline \multicolumn{2}{l}{ Symmetric Difference (Error \%) between Water Surface Profiles } & $17.76 \%$ \\
\hline \multicolumn{2}{l}{ Parametric Paired-T Test $p$-value (at 0.05 significance level) } & 0.039 \\
\hline
\end{tabular}


Figure 9. Water surface extents for the airborne (red) and composite (yellow) LiDAR datasets. (a) Study area. The dashed boxes represent the location of (b) and (c); (b) Expanded area indicated by the northern dashed box in the study area figure; (c) Expanded area indicated by the southern dashed box in the study area figure.

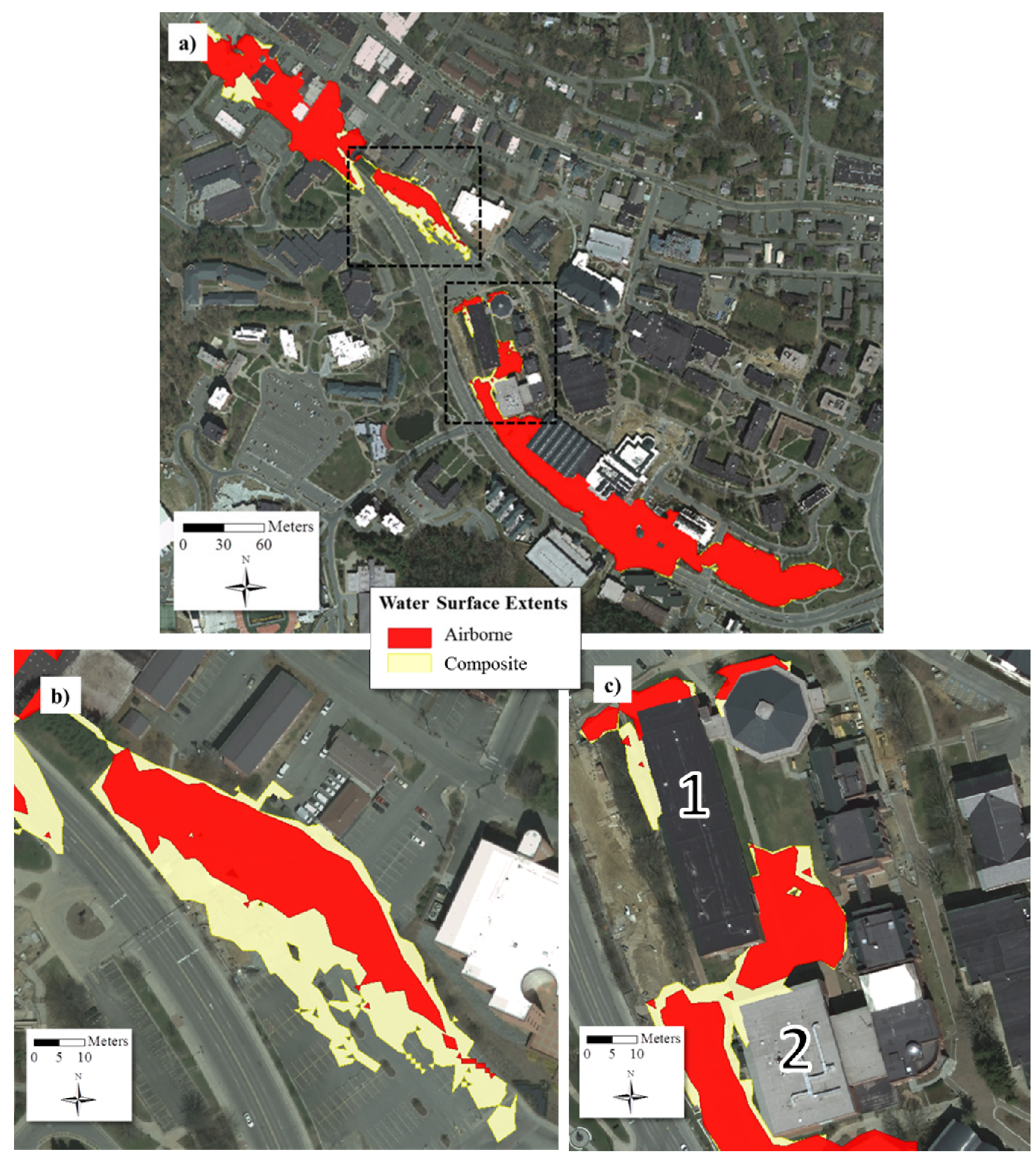


Figure 10. Depth grids generated using HEC-RAS, HEC-GeoRAS, and ArcGIS. (a) Depth grid (shaded purple) generated using bare-earth airborne LiDAR data; (b) Depth grid (shaded blue) generated using the bare-earth composite LiDAR data.
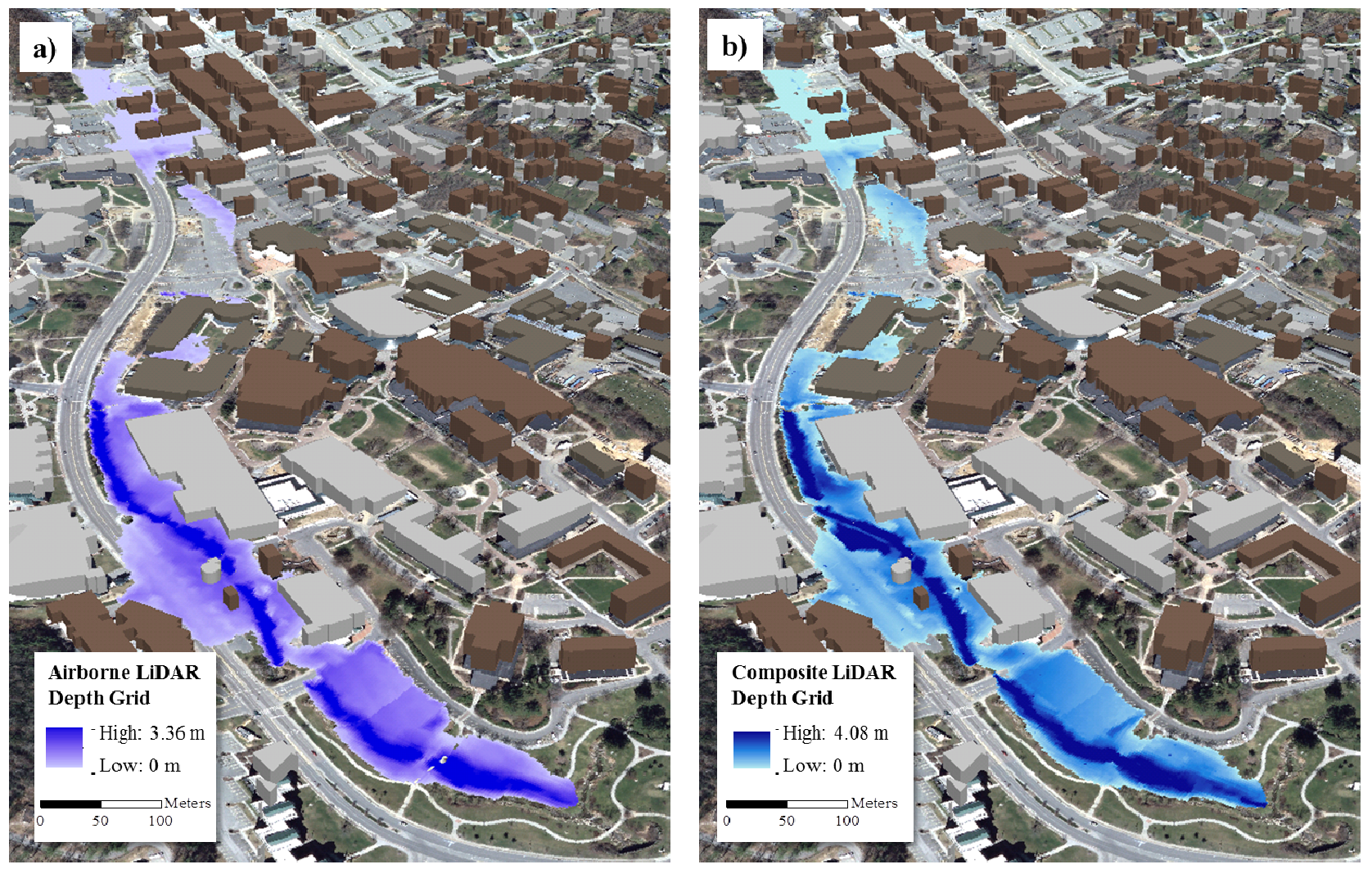

Table 6. Quantitative differences between the depth grids generated using the bare-earth airborne and composite LiDAR datasets.

\begin{tabular}{lccc}
\hline \multicolumn{1}{c}{ Statistics } & Airborne & Composite & Percent Different \\
\hline Volume $\left(\mathrm{m}^{3}\right)$ & $28,800.51$ & $29,696.98$ & $3.06 \%$ \\
Maximum Flood Height $(\mathrm{m})$ & 3.36 & 4.81 & $35.37 \%$ \\
\hline Root Mean Squared Error (RMSE) between Airborne and Composite & $1.36 \mathrm{~m}$ \\
\hline
\end{tabular}

The percent difference between the volume of the airborne LiDAR-derived depth grid and the composite-LiDAR derived depth grid was 3.06\% which translates into approximately $890 \mathrm{~m}^{3}$ of water (Table 6). To visually enhance the differences between the two depth grids and depict the location of those differences, the composite LiDAR-derived depth grid was subtracted from the airborne LiDAR-derived depth grid (Figure 11). Within the difference raster layer (Figure 11), areas containing dark blue represent locations where the airborne depth grid was greater than the composite depth grid indicating an overestimation of the volume of water for that particular area using only the airborne data. The regions containing red indicate locations where the composite depth grid was greater than the airborne depth grid. Supplementing the airborne dataset with mobile and terrestrial LiDAR in areas where the airborne data were no longer accurate improved topographic representations and flood modeling results. Although the difference in volume measurements recorded for the two datasets seemed small, the variation in flood model results displays the magnitude at which these differences can affect the products of the models. 
Figure 11. Difference between the depth grids generated using the bare-earth airborne LiDAR data and bare-earth composite LiDAR data, derived by subtracting the composite depth grid from the airborne depth grid. Areas containing dark blue represent locations where the airborne depth grid was greater than the composite depth grid. Areas containing red indicate locations where the composite depth grid was greater than the airborne depth grid.

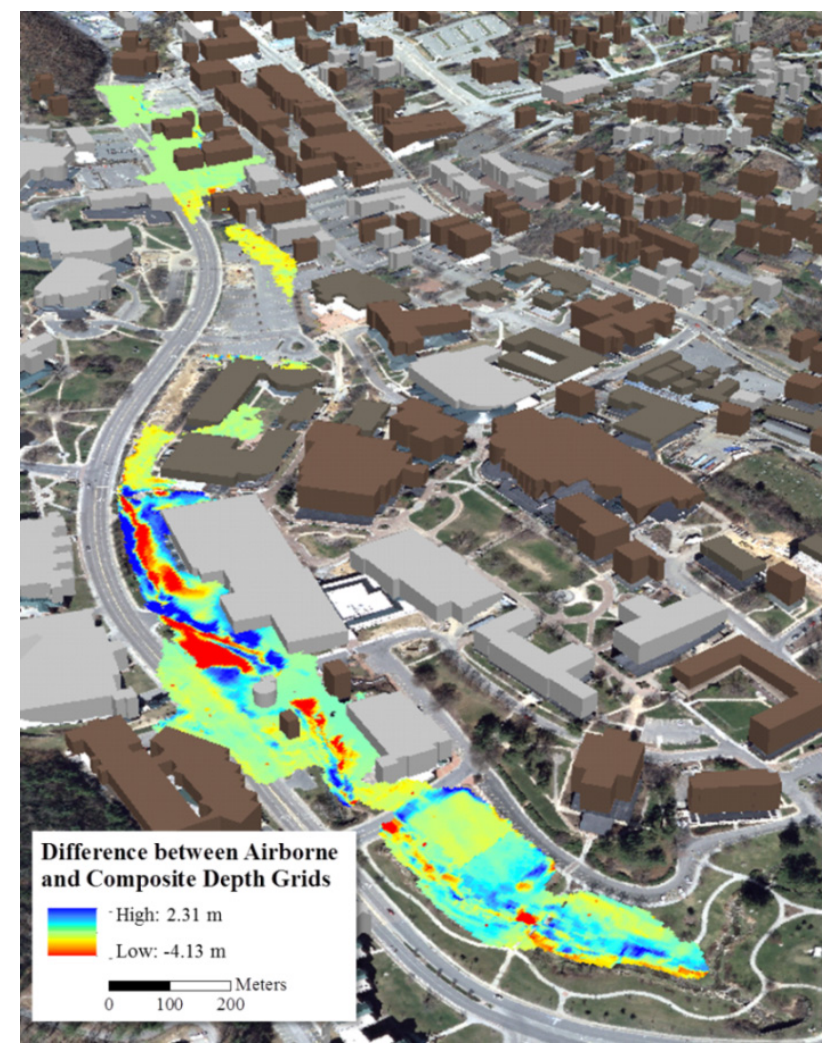

The accuracy of the terrain dataset is critical when delineating the 100-year floodplain or any return period flood, and for identifying structures that may be flooded during heavy precipitation events. Examples of these differences are illustrated in Figure 9. Several structures shown outside the flood extent delineated using the airborne LiDAR dataset are shown as flooded at the same discharge level using the composite LiDAR dataset. Less accurate representation of topography and complex features in an urban environment can have a significant effect on flood modeling results. An example of this lack of precision can be seen in Figure 9c. The water surface profiles indicating flooding extent vary in relation to the two buildings shown. A greater flood extent is illustrated on the west side of building 1 using the composite LiDAR elevation data (yellow) as compared to the airborne LiDAR-derived water surface profile (red). Additionally, for building 2, flooding extent derived using the airborne LiDAR data (red) illustrates that the building will not be affected by the 100-year discharge water levels while the composite LiDAR water surface extent (yellow) illustrates that the building will be affected and preparations can be made accordingly. In November 2011, the study area experienced a large precipitation event which flooded the first floor of both buildings as well as the adjacent parking lot. A direct measurement of precipitation levels and discharge rates for this event were not acquired due to a lack of instrumentation and the "flashy" nature of the stream, therefore, a quantitative accuracy assessment was not conducted. However, empirical assessments (based on eyewitness accounts) were made about the accuracy of the composite LiDAR-derived flood modeling results. 
The results from the flood modeling comparisons are not entirely consistent with previous flood inundation research using LiDAR elevation data. Wang and Zheng [60] and Cook and Merwade [26] found that coarsening the resolution of the topographic dataset increased the area of the water surface profiles as well as the maximum depth and volume of flood waters. These studies were conducted in both narrow-valleys and flat floodplains using resolutions as fine as $3 \mathrm{~m}$ [26]. Colby and Dobson [31] completed two studies in the mountains and plains of North Carolina and found generally similar results in relation to the increase in area of water surface profiles when coarsening data resolution, but found differing results in relation to the volume of flood waters in the mountains, concluding that the differences were due to a difference in data source as well as topographic data resolution. Conversely, $\mathrm{Li}$ and Wong [61] found a decrease in maximum flood height and water surface extent when coarsening the terrain dataset resolution in the rolling hills of Kansas using a finest resolution of $2 \mathrm{~m}$. Abdullah et al. [62] found similar results, citing low resolution digital elevation models yielded shallower floodwater depths; this was typically due to the loss of detailed landscape properties in the airborne dataset which affected floodwater transport [62].

A comparison of research efforts in this area between various authors is difficult in that the results of a flood inundation analysis depend on multiple input parameters (i.e., data source, topographic data resolution, discharge levels, water surface elevations, geometric data), geomorphic-hydrologic and landscape characteristics (e.g., length and width of the study stream reach, drainage basin topography, surrounding land cover), hydraulic models (i.e., 1D, 1D/2D or 2D), and diagnostic methods.

\section{Conclusions and Future Research}

In this paper, the utility of a high resolution ground-based LiDAR terrain dataset supplemented with a medium to low resolution airborne LiDAR terrain dataset for a flood inundation study in a GIS and hydraulic modeling environment was presented. Multi-platform LiDAR data consisting of airborne, mobile, and terrestrial bare-earth points were merged into one composite triangulated irregular network (TIN) to form a seamless representation of the study stream reach and adjacent terrain. A separate TIN consisting solely of bare-earth airborne LiDAR data was also generated, and a comprehensive quantitative comparison was made between the elevation values of the composite and airborne LiDAR datasets. A flood inundation analysis was conducted utilizing both the composite and airborne LiDAR datasets. The all-return ground-based LiDAR point clouds were used to obtain structural information for bridges and culverts that intersected the study stream reach enabling a more accurate model of features in the study area. The flood modeling results (i.e., water surface extents and depth grids) were quantitatively compared using several diagnostic methods.

A comparison of the elevation values in the two LiDAR datasets indicated differences in landscape characterization. When comparing values across three land surface features (pavement, grass, and slope), the greatest differences were found on sloping terrain. A mean difference of $0.178 \mathrm{~m}$ and a maximum difference of $1.677 \mathrm{~m}$ were calculated between the datasets based on 120 sample points randomly distributed throughout the study area. An evaluation of 12 cross-section profiles drawn perpendicular to the stream illustrated approximate horizontal (e.g., $3.2 \mathrm{~m}$ ) and vertical (e.g., $1 \mathrm{~m}$ ) offsets of the stream centerline. 
Through the combination of multi-platform LiDAR data and its use in a hydraulic flood modeling analysis, a 35\% increase in maximum flood height using the composite LiDAR dataset compared to the airborne LiDAR dataset was observed. The distances flooded along transects drawn perpendicular to the stream were found to be statistically significantly different between the water surface profiles generated using the composite and airborne terrain datasets. Additionally, a $17.76 \%$ symmetric difference value was calculated indicating a notable difference in the area and shape of the two water surface profiles. The results of this research indicated an underestimation of flood extents and volumes while using the airborne LiDAR data.

While flood modeling may generally be accurate in rural or homogenous areas using the airborne LiDAR data, the effects of complex terrain and features such as buildings and infrastructure that affect floodwater direction and flow in more urban environments could create inaccuracies while generating flood maps. The unique "flashy" character with potentially high flow volumes of the mountainous sub-basin in which this study occurred make an accurate representation of the topography for flood modeling more important. The addition of high resolution data from ground-based LiDAR sensors can supplement existing airborne data in topographically complex or sensitive urban areas to increase accuracy of the flood level predictions which will assist in better informing local populations of their potential risks.

An important challenge in using LiDAR data is the computational requirements necessary to handle such dense datasets. The workflow presented in this study provides researchers with less than optimal computational power a method to achieve reliable results. It is believed that the methods presented in this paper, namely the synthesis of airborne, mobile, and terrestrial LiDAR data in a GIS and hydraulic modeling environment, provide a robust method for accurately representing an urban floodplain and the subsequent flood modeling results dictate the need to better represent such a complex environment to indicate potential flood inundation locations. Further exploration of the application of mobile and terrestrial LiDAR data for urban flood modeling in a mountainous environment is warranted.

The airborne LiDAR data used in this study represents the first statewide available dataset acquired in the U.S., and the previous and continued application of this data has greatly benefited residents and businesses in North Carolina. Higher accuracy airborne LiDAR datasets have since been acquired in other states, and a comparison between these datasets or a QL 2 LiDAR dataset as recommended by the NEEA, and a composite LiDAR dataset similar to that used in this study for urban flood modeling would be valuable. Also, flood modeling using only high resolution LiDAR datasets would likely benefit from further analysis using $1 \mathrm{D} / 2 \mathrm{D}$ or $2 \mathrm{D}$ hydraulic models.

\section{Acknowledgements}

The authors would like to thank ESP Associates, P.A. for acquiring and donating the ground-based LiDAR data for this research. The authors would also like to thank QCoherent for their donation of an LP360 license to Appalachian State University. Additional thanks are due to Christopher Badurek and Art Rex for their assistance.

This research was supported by the College of Arts and Sciences at Appalachian State University. 


\section{Conflicts of Interest}

The authors declare no conflict of interest.

\section{References}

1. White, G.F. Human Adjustment to Floods: A Geographical Approach to the Flood Problem in the United States; Research Paper No. 29; University of Chicago, Department of Geography: Chicago, IL, USA, 1942.

2. National Research Council of the National Academies. 1: Introduction. In Mapping the Zone: Improving Flood Map Accuracy; The National Academies Press: Washington, DC, USA, 2009; pp. 1-12.

3. Wohl, E.E. Chapter 1: Inland flood hazards. In Inland Flood Hazards: Human, Riparian, and Aquatic Communities; Wohl, E.E., Ed.; Cambridge University Press: New York, NY, USA, 2011; pp. 3-36.

4. European Commission. A New EU Floods Directive. Available online: http:/ec.europa.eu/ environment/water/flood_risk/ (accessed on 29 July 2013).

5. Mark, O.; Weesakul, S.; Apirumanekul, C.; Aroonnet, S.B.; Djordjevic, S. Potential and limitations of 1D modeling of urban flooding. J. Hydrol. 2004, 299, 284-299.

6. Yu, D.; Lane, S.N. Urban fluvial flood modeling using a two-dimensional diffusion-wave treatment, Part 2: Development of a sub-grid-scale treatment. Hydrol. Process. 2006, 20, 1567-1583.

7. Bates, P. Remote sensing and flood inundation modelling. Hydrol. Process. 2004, 18, 2539-2597.

8. Hollaus, M.; Wagner, W.; Kraus, K. Airborne laser scanning and usefulness for hydrological models. Adv. Geosci. 2005, 5, 57-63.

9. Bremer, M.; Sass, O. Combining airborne and terrestrial laser scanning for quantifying erosion and deposition by a debris flow event. Geomorphology 2012, 128, 49-60.

10. Hunter, N.; Bates, P.; Neelz, S.; Pender, G.; Villanueva, I.; Wright, N.; Liang, D.; Falconer, R.; Lin, B.; Waller, S.; et al. Benchmarking 2D hydraulic models for urban flooding. Water Manag. 2008, 161, 13-30.

11. McMillan, H.; Brasington, J. Reduced complexity strategies for modelling urban floodplain inundation. Geomorphology 2009, 90, 226-243.

12. Vojinovic, Z; Tutulic, D. On the use of 1D-2D modelling approaches for assessment of flood damage in urban areas. Urban Water J. 2009, 6, 183-199.

13. Haile, A.T.; Rientjes, T.H.M. Effects of LiDAR DEM Resolution in Flood Modelling: A Model Sensitivity Study for the City of Tegucigalpa, Honduras; ISPRS WG III/3, III/4, V/3 Workshop: Enschede, The Netherlands, 2005; pp. 169-173.

14. Fewtrell, T.J.; Duncan, A.; Sampson, C.C.; Neal, J.C.; Bates, P.D. Benchmarking urban flood models of varying complexity and scale using high resolution terrestrial LiDAR data. Phys. Chem. Earth 2011, 36, 281-291.

15. Sampson, C.; Bates, P.; Duncan, A.; Fewtrell, T. Merging Airborne and Terrestrial LiDAR Data to Determine Geometric Controls on Flood Propagation in Urban Areas; EGU2011-13739; European Geoscience Union General Assembly: Vienna, Austria, 2011. 
16. Brasington, J.; Vericat, D.; Rychkov, I. Modeling river bed morphology, roughness, and surface sedimentology using high resolution terrestrial laser scanning. Water Resour. Res. 2012, 48, doi:10.1029/2012WR012223.

17. Hoshenthal, J.; Alho, P.; Hyyppa, J.; Hyyppa, H. Laser scanning applications in fluvial studies. Prog. Phys. Geogr. 2011, 35, 782-809.

18. Wehr, A. Airborne laser scanning-An introduction and overview. ISPRS J. Photogramm. Remote Sens. 1999, 54, 68-82.

19. Dewberry. Final Report of the National Enhanced Elevation Assessment; Dewberry: Fairfax, VA, USA, 2011 (revised 2012). Available online: http://www.dewberry.com/files/pdf/NEEA_Final\% 20Report_Revised\%203.29.12.pdf (accessed on 29 June 2013).

20. National Research Council. Elevation data for floodplain mapping; The National Academies Press: Washington, DC, USA, 2007.

21. Merwade, V.; Olivera, F.; Arabi, M.; Edleman, S. Uncertainty in flood inundation mapping: Current issues and future directions. J. Hydrol. Eng. 2008, 13, 608-620.

22. Marks, K.; Bates, P.D. Integration of high-resolution topographic data with floodplain flow models. Hydrol. Process. 2000, 14, 2109-2122.

23. Manson, S.M.; Ratick, S.J.; Solow, A.R. Decision making and uncertainty: Bayesian analysis of potential flood heights. Geogr. Anal. 2002, 34, 112-129.

24. Omer, C.R.; Nelson, E.J.; Zundel, A.K. Impact of varied data resolution on hydraulic modeling and floodplain delineation. J. Am. Water Resour. Assoc. 2003, 39, 467-475.

25. Casas, A.; Benito, G.; Thorndycraft, V.R.; Rico, M. The topographic data source of digital terrain models as a key element in the accuracy of hydraulic flood modeling. Earth Surf. Process. Landf. 2006, 31, 444-456.

26. Cook, A.; Merwade, V. Effect of topographic data, geometric configuration and modeling approach on flood inundation mapping. J. Hydrol. 2009, 377, 131-142.

27. Fewtrell, T.J.; Bates, P.D.; Horritt, M.; Hunter, N.M. Evaluating the effect of scale in flood inundation modelling in urban environments. Hydrol. Process. 2008, 22, 5107-5118.

28. Gallegos, H.A.; Schubert, J.E.; Sanders, B.F. Two-dimensional, high-resolution modeling of urban dam-break flooding: A case study of Baldwin Hills, California. Adv. Water Resour. 2009, 32, 1323-1335.

29. Webster, T. Flood risk mapping using LiDAR for Annapolis Royal, Nova Scotia, Canada. Remote Sens. 2010, 2, 2060-2082.

30. Marcus, W.A.; Aspinall, R.J.; Marston, R.A. Geographic Information Systems and Surface Hydrology. In Geographic Information Science and Mountain Geomorphology; Bishop, M.P., Shroder, J.F., Jr., Eds.; Springer: New York, NY, USA, 2005; pp. 343-379.

31. Colby, J.D.; Dobson, J.G. Flood modeling in the coastal plains and mountains: Analysis of terrain resolution. Nat. Hazards Rev. 2010, 11, 19-28.

32. Iavarone, A.; Vagners, D. Sensor fusion: Generating 3D by combining airborne and tripod-mounted LIDAR data. In Proceedings of the International Workshop on Visualization and Animation of Reality-Based 3D Models 2003, International Archives of the Photogrammetry, Remote Sensing and Spatial Information Sciences, Engadin, Switzerland, 24-28 February 2003; Volume 34-5/W10. 
33. Böhm, J.; Haala, N. Efficient Integration of Aerial and Terrestrial Laser Data for Virtual City Modeling Using LASERMAPS; ISPRS Volume 36 Part 3/W19; ISPRS Workshop Laser Scanning: Enschede, The Netherlands, 2005; pp. 192-197.

34. Van Leeuwen, M.; Hilker, T.; Coops, N.C.; Frazer, G.W.; Wulder, M.A.; Newnham, G.J.; Culvenor, D.S. Assessment of standing wood and fiber quality using ground and airborne laser scanning: A review. For. Ecol. Manag. 2011, 261, 1467-1478.

35. Kasvi, E.; Vaaja, M.; Alho, P.; Hyyppa, H.; Hyyppa, J.; Kaartinen, H.; Kukko, A. Morphological changes on meander bars associated with flow structure at different discharges. Earth Surf. Process. Landf. 2013, 38, 577-590.

36. Methods, H.; Dyhouse, G.; Hatchett, J.; Benn, J. Chapter 6: Bridge Modeling. In Floodplain Modeling Using HEC-RAS, 1st ed.; Totz, C., Klotz, D., Strafaci, A., Hogan, A., Dietrich, K., Eds.; Haestad Press: Waterbury, CT, USA, 2003; pp. 167-231.

37. Methods, H.; Dyhouse, G.; Hatchett, J.; Benn, J. Chapter 7: Culvert Modeling. In Floodplain Modeling Using HEC-RAS, 1st ed.; Totz, C., Klotz, D., Strafaci, A., Hogan, A., Dietrich, K., Eds.; Haestad Press: Waterbury, CT, USA, 2003; pp. 233-281.

38. Chang, J.; Tsai, M.; Findley, D.; Cunningham, C. North Carolina Department of Transportation Research Project No. 2012-15: Infrastructure Investment Protection with LiDAR; FHWA/NC/2012-15; North Carolina Department of Transportation Research and Analysis Group: Raleigh, NC, USA, 2012; pp. 1-84.

39. Pielke, R.A., Jr.; Downton, M.W.; Miller, J.Z.B. Flood Damage in the United States, 1926-2000: A Reanalysis of National Weather Service Estimates; University Corporation for Atmospheric Research (UCAR): Boulder, CO, USA, 2002; pp. 1-86.

40. Bales, J.D.; Wagner, C.R.; Tighe, K.C.; Terziotti, S. LiDAR-Derived Flood-Inundation Maps for Real-Time Flood-Mapping Applications, Tar River basin, North Carolina; U.S. Geological Survey Scientific Investigations Report 2007-5032; U.S. Geological Survey: Reston, VA, USA, 2007; pp. $1-52$.

41. Coffey, C. The Effects of Impervious Surfaces and Forests on Water Quality in a Southern Appalachian Headwater Catchment: A Geospatial Modeling Approach; Master's Thesis, Appalachian State University, Boone, NC, USA, August 2011.

42. Wohl, E.E.; Mountain Rivers, Water Resources Monograph; American Geophysical Union: Washington, DC, USA, 2000; Volume 14, pp. 1-320.

43. Anderson, W.P.; Anderson, J.L.; Thaxton, C.S.; Babyak, C.M. Changes in stream temperatures in response to restoration of groundwater discharge and solar heating in a culverted, urban stream. J. Hydrol. 2010, 393, 309-320.

44. NC Geographic Information Coordinating Council. NC OneMap, Discover/Get Geospatial Data. Available online: http://www.nconemap.com/DiscoverGetData.aspx (accessed on 1 May 2012).

45. State Climate Office of North Carolina. Overview. Available online: http://www.nc-climate.ncsu.edu/ climate/ncclimate.html (accessed on 20 March 2012).

46. Floodplain Mapping Program, North Carolina Division of Emergency Management. NC Floodplain Mapping: Watauga River Basin; LiDAR Bare Earth Mass Points, Feb-Apr and Dec 2003; EarthData International of North Carolina: High Point, NC, USA, 2004. Available online: http://floodmaps.nc.gov/fmis/Download.aspx?FIPS=189 (accessed on 1 October 2011). 
47. North Carolina Floodplain Mapping Program. Floodplain Mapping Information System. Available online: http://floodmaps.nc.gov/fmis/Download.aspx (accessed on 1 September 2011).

48. National Geodetic Survey. Continuously Operating Reference Station (CORS). Available online: http://geodesy.noaa.gov/CORS/ (accessed on 1 September 2011).

49. Applanix Corp. POSPac Mobile Mapping Suite. Available online: http://www.applanix.com/ products/land/pospac-mms.html (accessed on 1 October 2011).

50. Axelsson, P. Processing of laser scanner data-Algorithms and applications. ISPRS J. Photogramm. Remote Sens. 1999, 54, 138-137.

51. U.S. Geological Survey (USGS). Endorsement for a 3D Elevation Program by the National Digital Elevation Program (NDEP). Available online: http://nationalmap.gov/3DEP/documents/ ndep_endorsement_dec2012.pdf(accessed on 25 June 2013).

52. Methods, H.; Dyhouse, G.; Hatchett, J.; Benn, J. Chapter 1: Introduction to Floodplain Modeling and Management. In Floodplain Modeling Using HEC-RAS, 1st ed.; Totz, C., Klotz, D., Strafaci, A., Hogan, A., Dietrich, K., Eds.; Haestad Press: Waterbury, CT, USA, 2003; pp. 167-231.

53. US Army Corps of Engineers. HEC-RAS River Analysis System, User's Manual; U.S. Army Corps of Engineers, Hydrologic Engineering Center, Institute for Water Resources: Davis, CA, USA, 2010.

54. Johnson, L.E. 9: GIS for Floodplain Management. In Geographic Information Systems in Water Resource Engineering; Taylor and Francis, LLC: Boca Raton, FL, USA, 2009; pp. 187-206.

55. Federal Emergency Management Agency State of North Carolina. Flood Insurance Study: A Report of Flood Hazards in Watauga County, North Carolina and Incorporated Areas; FEMA: Atlanta, GA, USA, 2009; pp. 1-218.

56. US Army Corps of Engineers. HEC-GeoRAS. Available online: http://www.hec.usace.army.mil/ software/hec-georas (accessed on 1 June 2011).

57. Chow, V.T. Open-Channel Hydraulics; McGraw-Hill Book Co., Inc.: New York, NY, USA, 1959.

58. US Army Corps of Engineers (USACE); Hydrologic Engineering Center. HEC-RAS River Analysis System: Hydraulic Reference Manual; Version 4.1; USACE: Davis, CA, USA, 2010.

59. Gueudet, P.; Wells, G.; Maidment, D.; Neuenschwander, A. Influence of the post-spacing of the LiDAR-derived DEM on flood modeling. In Proceedings of 2004 American Water Resources Association Spring Specialty Conference, GIS and Water Resources III, Nashville, TN, USA, 17 May 2004; pp. 1-5.

60. Wang, Y.; Zheng, T. Comparison of light detection and ranging and nation elevation dataset digital elevation model on floodplains of North Carolina. Nat. Hazards Rev. 2005, 6, 34-40.

61. Li, J.; Wong, D.W.S. Effects of DEM sources on hydrologic applications. Comput. Environ. Urban Syst. 2010, 34, 251-261.

62. Abdullah, A.F.; Vojinovic, Z.; Price, R.K.; Aziz, N.A.A. A methodology for processing raw LiDAR data to support urban flood modelling framework. J. Hydroinforma. 2012, 14, 75-92.

(a) 2013 by the authors; licensee MDPI, Basel, Switzerland. This article is an open access article distributed under the terms and conditions of the Creative Commons Attribution license (http://creativecommons.org/licenses/by/3.0/). 